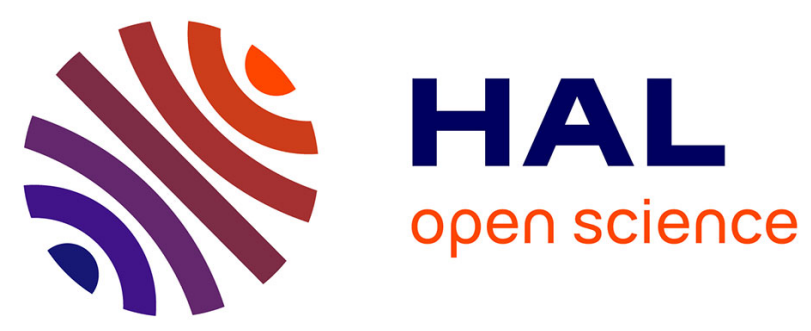

\title{
In vitro liver metabolism of aclidinium bromide in preclinical animal species and humans: identification of the human enzymes involved in its oxidative metabolism
}

\author{
Joan J. Albertí, Sònia Sentellas, Miquel Salvà
}

\section{- To cite this version:}

Joan J. Albertí, Sònia Sentellas, Miquel Salvà. In vitro liver metabolism of aclidinium bromide in preclinical animal species and humans: identification of the human enzymes involved in its oxidative metabolism. Biochemical Pharmacology, 2011, 81 (6), pp.761. 10.1016/j.bcp.2010.12.013 . hal00672297

\section{HAL Id: hal-00672297 \\ https://hal.science/hal-00672297}

Submitted on 21 Feb 2012

HAL is a multi-disciplinary open access archive for the deposit and dissemination of scientific research documents, whether they are published or not. The documents may come from teaching and research institutions in France or abroad, or from public or private research centers.
L'archive ouverte pluridisciplinaire $\mathbf{H A L}$, est destinée au dépôt et à la diffusion de documents scientifiques de niveau recherche, publiés ou non, émanant des établissements d'enseignement et de recherche français ou étrangers, des laboratoires publics ou privés. 


\section{Accepted Manuscript}

Title: In vitro liver metabolism of aclidinium bromide in preclinical animal species and humans: identification of the human enzymes involved in its oxidative metabolism

Authors: Joan J. Albertí, Sònia Sentellas, Miquel Salvà

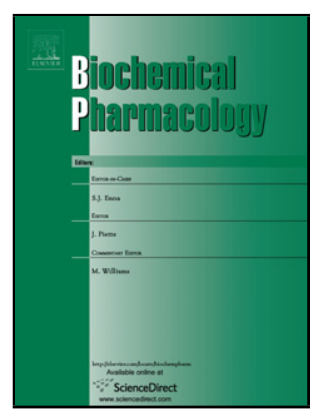

PII:

S0006-2952(10)00878-6

DOI: doi:10.1016/j.bcp.2010.12.013

Reference: BCP 10779

To appear in: $\quad B C P$

Received date: $\quad 28-10-2010$

Revised date: $\quad 9-12-2010$

Accepted date: $\quad$ 10-12-2010

Please cite this article as: Albertí JJ, Sentellas $\mathrm{S}$, Salvà M, In vitro liver metabolism of aclidinium bromide in preclinical animal species and humans: identification of the human enzymes involved in its oxidative metabolism, Biochemical Pharmacology (2010), doi:10.1016/j.bcp.2010.12.013

This is a PDF file of an unedited manuscript that has been accepted for publication. As a service to our customers we are providing this early version of the manuscript. The manuscript will undergo copyediting, typesetting, and review of the resulting proof before it is published in its final form. Please note that during the production process errors may be discovered which could affect the content, and all legal disclaimers that apply to the journal pertain. 


\section{In vitro liver metabolism of aclidinium bromide in}

\section{preclinical animal species and humans: identification of}

\section{the human enzymes involved in its oxidative metabolism}

Joan J. Albertí, Sònia Sentellas, and Miquel Salvà

Department of Pharmacokinetics and Drug Metabolism, Almirall, S.A.

Sant Feliu de Llobregat, Barcelona, Spain

Corresponding author:

Dr. Joan Albertí

Department of Pharmacokinetics and Drug Metabolism, Almirall, S.A.

Laureà Miró 408-410

08980 Sant Feliu de Llobregat (Barcelona)

Spain

Tel.: +34932912948

Fax: +34 932912997

E-mail address: joan.alberti@almirall.com

Category: (8) Pharmacokinetics \& Drug Metabolism 


\section{Abbreviations}

$A B$, aclidinium bromide

BChE, butyrylcholinesterase

CID, collision-induced dissociation

P450, cytochrome P450

$\mathrm{ESI}$, electrospray ionization

FMO, flavin-containing monooxigenases

glyc, glycolyl

$\mathrm{K}_{\mathrm{h}}$, hydrolysis rate constant

LC, liquid chromatography

MRM, multiple reaction monitoring

MS, mass spectrometry

$\mathrm{m} / \mathrm{z}$, mass-to-charge ratio

phe, phenyl

SPE, solid-phase extraction

TEA, triethylamine 


\section{Abstract}

The metabolism of aclidinium bromide, a novel long-acting antimuscarinic drug for the maintenance treatment of chronic obstructive pulmonary disorder, has been investigated in liver microsomes and hepatocytes of mice, rats, rabbits, dogs, and humans. Due to the rapid hydrolysis of this ester compound, two distinct radiolabeled forms of aclidinium were studied. The main biotransformation route of aclidinium was the hydrolytic cleavage of the ester moiety, resulting in the formation of the alcohol metabolite (M2, LAS34823) and carboxylic acid metabolite (m3, LAS34850), which mainly occurred non-enzymatically. By comparison, the oxidative metabolism was substantially lower and the metabolite profiles were similar across all five species examined. Aclidinium was metabolized oxidatively to four minor primary metabolites that were identified as monohydroxylated derivatives of aclidinium at the phenyl (M4) and glycolyl (m4, m6 and $\mathrm{m} 7)$ moieties of the molecule. The NADPH-dependent metabolite $\mathrm{m} 4$ involved the loss of one of the thiophene rings of aclidinium. Incubations with human recombinant P450 isoforms and inhibition studies with selective chemical inhibitors and antibodies of human P450 enzymes demonstrated that the oxidative metabolism of aclidinium is primarily mediated by CYP3A4 and CYP2D6. Additionally, up to eight secondary metabolites were also characterized, involving further hydrolysis, oxidation, or glucuronidation of the primary metabolites. Also, the liver oxidative metabolism of the alcohol metabolite (LAS34823) resulted in the production of one hydroxylated metabolite (M1) mediated by human CYP2D6, whereas the acid metabolite (LAS34850) was not metabolized enzymatically, although a minor non-enzymatic and NADPH-dependent reduction was observed. 
Keywords: aclidinium bromide, in vitro metabolism, interspecies differences, enzyme identification.

\section{Introduction}

Aclidinium bromide (AB) (also known as 3R-(2-hydroxy-2,2-dithiophen-2-yl-acetoxy)1-(3-phenoxy-propyl)1-azonia bicyclo [2.2.2] octane bromide) is a novel, long-acting muscarinic antagonist [1] undergoing Phase III clinical trials for the maintenance treatment of chronic obstructive pulmonary disorder. This ester compound displayed non-enzymatic hydrolysis of its ester bond at neutral and basic $\mathrm{pH}$. Furthermore, $\mathrm{AB}$ was rapidly hydrolyzed in plasma of different animal species and humans to yield its alcohol (LAS34823) and carboxylic acid (LAS34850) metabolites [2, 3]. The main human esterase involved in the enzymatic hydrolysis of aclidinium was identified as butyrylcholinesterase (BChE), which is found mainly in human plasma. Cytochrome P450 (P450)-catalyzed ester cleavage was not observed in human liver microsomes [4].

In vitro incubations with liver microsomes and/or hepatocytes can be used to predict potential biotransformations in humans and in those animal species used for preclinical safety studies. Hepatocyte incubations retain Phase I and Phase II enzyme activities and are therefore useful in determining overall metabolism. They also mimic in vivo metabolism more accurately than incubations with subcellular fractions [5]. Previous data using diagnostic substrates have shown that P450 activities in rat, dog, monkey, and human hepatocyte suspensions are not significantly decreased by cryopreservation [6]. 
The objectives of this study were (a) to compare the in vitro metabolism of aclidinium in liver microsomes and hepatocytes of different preclinical animal species and humans; (b) to identify the oxidative metabolites; and (c) to identify and kinetically characterize the human enzymes responsible for the oxidative metabolism. Due to the hydrolysis mechanism, two distinct radiolabeled forms of aclidinium were prepared with the radioactive carbon-14 label incorporated into the phenyl or glycolyl moieties of the molecule (Figure 1). The phenotyping reaction of aclidinium and its hydrolysis metabolites was performed using human-expressed recombinant P450 isoforms and P450-specific chemical inhibitors and inhibitory antibodies. 


\section{Materials and Methods}

\subsection{Chemicals}

${ }^{14} \mathrm{C}$-phenyl-AB $\left({ }^{14} \mathrm{C}\right.$-phe-AB, $\left.30.2 \mathrm{mCi} / \mathrm{mmol}\right)$ and ${ }^{14} \mathrm{C}$-glycolyl-AB $\left({ }^{14} \mathrm{C}\right.$-glyc-AB, 26.0 $\mathrm{mCi} / \mathrm{mmol}$ ) were synthesized at Quotient BioResearch Ltd (Northamptonshire, UK). The radiolabeled hydrolysis products ${ }^{14} \mathrm{C}$-LAS34823 $(23.9 \mathrm{mCi} / \mathrm{mmol})$ and ${ }^{14} \mathrm{C}$ LAS34850 $(24.4 \mathrm{mCi} / \mathrm{mmol})$ were prepared by basic hydrolysis from ${ }^{14} \mathrm{C}-$ phe-AB and ${ }^{14} \mathrm{C}$-glyc-AB, respectively, and further purification (Pharmacokinetics \& Drug Metabolism Department, Almirall S.A., Barcelona, Spain). All radiolabeled compounds exhibited purity over $98 \%$ (determined by liquid chromatography [LC] with UV and radiometric detection). Stock solutions of $5 \mathrm{mM}{ }^{14} \mathrm{C}$-phe-AB and $5 \mathrm{mM}$ ${ }^{14} \mathrm{C}$-glyc-AB were prepared in $0.1 \mathrm{~N} \mathrm{HCl}$ :acetonitrile $(10: 90, \mathrm{v} / \mathrm{v})$. Stock solutions of 5 $\mathrm{mM}{ }^{14} \mathrm{C}$-LAS34823 and $10 \mathrm{mM}{ }^{14} \mathrm{C}$-LAS34850 were prepared in aqueous basic solution containing $20 \%$ acetonitrile. Non-radiolabeled aclidinium (>99\% purity), its alcohol metabolite (LAS34823; [3(R)-hydroxy-1-(3-phenoxy-propyl)-1-azoniabicyclo[2.2.2]octane, bromide]) and its carboxylic acid metabolite (LAS34850; [dithienyl-glycolic acid, sodium salt]), LAS188638 and LAS101563 standards were synthesized at Ranke Química S.L. (Barcelona, Spain). Working solutions of ${ }^{14} \mathrm{C}$ phe- $A B$ and ${ }^{14} \mathrm{C}-$-glyc- $A B$ were prepared daily before use in $0.01 \mathrm{~N} \mathrm{HCl}$ :acetonitrile $(80: 20, \mathrm{v} / \mathrm{v})$ to prevent aclidinium hydrolysis. LC-grade methanol, acetonitrile, dimethylsulphoxide (DMSO), and triethylamine (TEA) were obtained from Scharlab S.L. (Barcelona, Spain). Glucose-6-phosphate, NADP ${ }^{+}$, glucose-6-phosphate dehydrogenase, 2-thiopheneglyoxylic acid, dithienyl-2-ketone, and Krebs-Henseleit medium with D-glucose were purchased from Sigma-Aldrich (Steinheim, Germany). Williams' E medium and other chemicals used in hepatocyte incubations were 
purchased from Gibco Invitrogen (Paisley, UK). All other chemicals used were purchased from Sigma-Aldrich (Steinheim, Germany).

\subsection{Biological materials}

CD-1 mouse (male and female), Sprague-Dawley rat (male and female), New Zealand white rabbit (female), Beagle dog (male), and human (mixed gender, $\mathrm{n}=50$ ) liver microsomes were purchased from XenoTech (Lenexa, KS, USA). CD-1 mouse (male), Wistar rat (male), New Zealand white rabbit (female) and human (mixed gender, $\mathrm{n}=10$ donors) cryopreserved hepatocytes were purchased from Celsis International (Chicago, USA). Cryopreserved Beagle dog (male) hepatocytes were purchased from XenoTech. Recombinant human P450 (CYP1A1, 1A2, 2C8, 2C9*1, $2 \mathrm{C} 19 * 1,2 \mathrm{~A} 6,2 \mathrm{~B} 6,2 \mathrm{D} 6 * 1,2 \mathrm{E} 1,3 \mathrm{~A} 4,3 \mathrm{~A} 5,4 \mathrm{~A} 11,2 \mathrm{~F} 2,4 \mathrm{~F} 3 \mathrm{~A}, 4 \mathrm{~F} 3 \mathrm{~B})$ and flavincontaining monooxigenases (FMO1, FMO3, and FMO5) expressed in microsomes of baculovirus-infected cells (Supersomes ${ }^{\mathrm{TM}}$ ) were obtained from BD Biosciences (San Jose, CA, USA). All the P450 isoforms contained NADPH-P450 reductase. Selective human P450 antibodies (CYP1A2, 2A6, 2B6, 2C8, 2D6, 2E1, and 3A4/5) were obtained from Gentest (Woburn, MA, USA).

\subsection{Liver microsome incubations}

All microsomal incubations were carried out in open-to-air polyethylene tubes at $37^{\circ} \mathrm{C}$ in a shaking water bath. Microsomal protein $(0.5 \mathrm{mg} / \mathrm{ml})$ in $50 \mathrm{mM}$ phosphate buffer ( $\mathrm{pH}$ 7.4) containing $3 \mathrm{mM} \mathrm{MgCl} 2,1 \mathrm{mM}$ EDTA, and cofactor generating system (1 mM NADP ${ }^{+}, 5$ mM glucose-6-phosphate and 2.5 units/ml glucose-6-phosphate 
dehydrogenase) were placed in a shaking water bath for 3 minutes at $37^{\circ} \mathrm{C}$.

Reactions were initiated by the addition of the test compounds $\left({ }^{14} \mathrm{C}\right.$-phe- $\mathrm{AB}$ and ${ }^{14} \mathrm{C}$ glyc-AB incubations) or NADPH-generating system $\left({ }^{14} \mathrm{C}\right.$-LAS34823 and ${ }^{14} \mathrm{C}$ LAS34850 incubations) to give a final incubation volume of $1 \mathrm{ml}$. Incubations were terminated by the addition of $0.5 \mathrm{ml}$ of ice-cold $0.2 \mathrm{~N} \mathrm{HCl}$. Aliquots of the incubation samples $(0.3 \mathrm{ml})$ in time-dependent studies were taken at different pre-defined times $(15,30$, and 60 minutes) and terminated by the addition of $0.15 \mathrm{ml}$ of ice-cold $0.2 \mathrm{~N}$ $\mathrm{HCl}$. Enzyme kinetics studies in human liver microsomes were performed under initial linear conditions with respect to incubation time (15 minutes for ${ }^{14} \mathrm{C}-$ phe-AB and ${ }^{14} \mathrm{C}$-glyc-AB and 30 minutes for ${ }^{14} \mathrm{C}$-LAS34823 and ${ }^{14} \mathrm{C}$-LAS34850) and microsomal protein concentration $\left(0.25 \mathrm{mg} / \mathrm{ml}\right.$ for ${ }^{14} \mathrm{C}$-phe-AB and ${ }^{14} \mathrm{C}$-glyc-AB and $0.5 \mathrm{mg} / \mathrm{ml}$ for ${ }^{14} \mathrm{C}$-LAS34823 and ${ }^{14} \mathrm{C}$-LAS34850). All incubations were carried out in duplicate, and the concentration of organic solvent (acetonitrile) was kept below $2 \%$ $(v / v)$. Parallel incubations were always performed in the incubation buffer as a nonenzymatic hydrolysis evaluation. Sample analysis was conducted using solid phase extraction (SPE)-LC system with radiometric detection.

\subsection{Hepatocyte incubations}

Immediately before use, hepatocytes were thawed according to the recommended protocol. In brief, frozen cells (approximately $5 \times 10^{6}$ cells/vial) were thawed quickly by gentle shaking in a $37^{\circ} \mathrm{C}$ water bath. Immediately after thawing, the hepatocyte suspension was diluted with Williams' E medium (pH 7.4) supplemented with $2.5 \mu \mathrm{M}$ dexamethasone, $4 \mathrm{\mu g} / \mathrm{ml}$ insulin, $100 \mathrm{units} / \mathrm{ml}$ penicillin, $100 \mu \mathrm{g} / \mathrm{ml}$ streptomycin, 2 $\mathrm{mM}$ glutamine, and $10 \%$ fetal bovine serum pre-warmed to $37^{\circ} \mathrm{C}$. After centrifugation 
$\left(25^{\circ} \mathrm{C}, 50 \mathrm{~g}, 5 \mathrm{~min}\right)$ and medium aspiration, the hepatocyte pellet was resuspended by gentle inversion in $2.0 \mathrm{ml}$ of pre-warmed Krebs-Henseleit buffer $(\mathrm{pH} 7.4)$ supplemented with $1 \mathrm{mM} \mathrm{CaCl}, 25 \% \mathrm{NaHCO}_{3}$, and $20 \mathrm{mM} \mathrm{HEPES}$, and diluted to $30 \mathrm{ml}$ with the same buffer and washed once. Hepatocyte viability was measured using the trypan blue exclusion method. The initial cell suspension was diluted at $2.1 \times 10^{6}$ viable cells/ml using Krebs-Henseleit buffer $(\mathrm{pH} 7.4)$. Incubations were conducted in suspension $\left(2 \times 10^{6}\right.$ viable cells $/ \mathrm{ml}$ in a total volume of $\left.0.1 \mathrm{ml}\right)$ for one and two hours in round-bottom glass tubes at $37^{\circ} \mathrm{C}$ in an atmosphere of $5 \% \mathrm{CO}_{2}$ and 95\% relative humidity (Forma Series $\mathrm{II} 3121, \mathrm{CO}_{2}$ water jacketed incubator, Thermo Scientific, Marietta, OH, USA). Radiolabeled test compounds were incubated at final concentrations of $20 \mu \mathrm{M}$. To minimize P450 inhibition, the concentration of organic solvent (acetonitrile) was kept below 1\% (v/v). Reactions were terminated by addition of $0.1 \mathrm{ml}$ of ice-cold acetonitrile/1N HCl $(90 / 10, \mathrm{v} / \mathrm{v})$ and incubation samples were immediately frozen at $-80^{\circ} \mathrm{C}$ until analysis using $\mathrm{LC}$ with radiometric detection. All incubations were performed in triplicate and parallel incubations with $75 \mu \mathrm{M} 7$ ethoxycoumarin were also performed as a positive control for phase I and II metabolism.

\subsection{Incubations with human recombinant $P 450$ and FMO isoforms}

The compounds ${ }^{14} \mathrm{C}$-Phe-LAS $34273(5 \mu \mathrm{M}),{ }^{14} \mathrm{C}$-Glyc-LAS $34273(5$ and $25 \mu \mathrm{M})$, and ${ }^{14} \mathrm{C}$-LAS $34823(5 \mu \mathrm{M})$ were incubated in duplicate at $37^{\circ} \mathrm{C}$ for $15 \mathrm{~min}, 30 \mathrm{~min}$ and $60 \mathrm{~min}$, respectively, with a panel of recombinant human P450 enzymes (CYP1A1, 1A2, 2B6, 2C8, 2C19, 2D6, 2E1, 3A4, 3A5, 4F2, 4F3A, 4F3B, CYP2A6, $2 \mathrm{C} 9$, and $4 \mathrm{~A} 11$ ) at $25 \mathrm{pmol}$ of $\mathrm{P} 450 /$ incubation and with recombinant FMO1, FMO2, 
and $\mathrm{FMO} 3$ at $0.2 \mathrm{mg}$ of protein/ml. Protein concentration in recombinant human P450 incubations was normalized $(0.25 \mathrm{mg} / \mathrm{ml})$ using insect control protein, without esterase and P450 activity. The incubation conditions and sample workup were similar to those described above (Section 2.3).

\subsection{Chemical and antibody inhibition studies}

Incubations were conducted in human liver microsomes as described above at the following test substance concentrations: $5 \mu \mathrm{M}\left({ }^{14} \mathrm{C}-\mathrm{LAS3} 3823\right), 5 \mu \mathrm{M}$ and $25 \mu \mathrm{M}$ $\left({ }^{14} \mathrm{C}\right.$-phe- $\mathrm{AB}$ and ${ }^{14} \mathrm{C}$-glyc- $\mathrm{AB}$, respectively) in a final volume of $1 \mathrm{ml}$. The selective chemical human P450 inhibitors assayed and final concentrations were $1 \mu \mathrm{M} \mathrm{\alpha -}$ naphthoflavone (CYP1A2), $2.5 \mu \mathrm{M}$ 8-methoxypsolaren (CYP2A6), $10 \mu \mathrm{M}$ quercetin (CYP2C8), $10 \mu \mathrm{M}$ sulfaphenazole (CYP2C9), $10 \mu \mathrm{M}$ omeprazole (CYP2C19), $10 \mu \mathrm{M}$ quinidine (CYP2D6), $2 \mu \mathrm{M}$ ketoconazole (CYP3A4), and $2.5 \mu \mathrm{M}$ 4-methylpyrazole (CYP2E1). After 3 minutes of pre-incubation at $37^{\circ} \mathrm{C}$, reactions were started by addition of the NADPH generating system $\left({ }^{14} \mathrm{C}\right.$-LAS34823) or the test substance $\left({ }^{14} \mathrm{C}\right.$-phe-AB and ${ }^{14} \mathrm{C}$-glyc-AB). After 15 minutes $\left({ }^{14} \mathrm{C}\right.$-phe-AB and ${ }^{14} \mathrm{C}$-glyc-AB) or 30 minutes $\left({ }^{14} \mathrm{C}\right.$-LAS34823), reactions were stopped by the addition of $0.5 \mathrm{ml}$ ice-cold $0.2 \mathrm{~N} \mathrm{HCl}$. Incubations in the presence of the irreversible CYP2A6 inhibitor 8methoxypsolaren were preceded by 15 minutes of pre-incubation time with NADPH before the addition of the test compounds. The final concentration of acetonitrile in the incubation mixtures was $0.7 \%$. To determine the effect of anti-P450 monoclonal antibodies on the metabolism of ${ }^{14} \mathrm{C}$-LAS34823, ${ }^{14} \mathrm{C}$-phe-AB, and ${ }^{14} \mathrm{C}$-glyc-AB, incubations were conducted in the presence of $5 \mu \mathrm{l}$ antibody $/ 100 \mathrm{mg}$ microsomal protein in all cases except for CYP3A4 antibody $(10 \mu \mathrm{l} / 100 \mathrm{mg})$. The different 
monoclonal human P450 antibodies were added to human liver microsomes $(0.5 \mathrm{ml})$ and incubated for 20 minutes on ice. Incubations were conducted as described above in a final volume of $1 \mathrm{ml}$. The final concentration of acetonitrile in the incubation mixtures was $0.2 \%$. All incubations were carried out in duplicate. Sample analysis was conducted using SPE-LC system with radiometric detection.

\subsection{LC analysis with radiometric detection}

Method A

Microsomal incubation samples were centrifuged for 10 minutes $\left(4^{\circ} \mathrm{C}\right)$ at $2,000 \mathrm{~g}$ (Heraeus Omnifuge 2.0RS, Heraeus Sepatech $\mathrm{GmbH}$, Osterode, Germany) and the supernatant $(1.5 \mathrm{ml})$ was analyzed by on-line SPE (Prospekt, Spark-Holland, Emmen, Netherlands) coupled to LC (Waters Alliance 2695 system, Milford, MA, USA) with radiometric flow scintillation detection (Packard 150TR, PerkinElmer, Downers Grove, IL, USA) and UV detection at 220 and 240 nm (Waters 2996 Photo Diode Array). Briefly, following activation of an SPE Waters Oasis HLB cartridge (10x2 mm, $30 \mu \mathrm{m}, 15 \mathrm{mg}$ ) with $1 \mathrm{ml}$ of methanol and conditioning with $1 \mathrm{ml}$ of pure water, incubation samples $(1.5 \mathrm{ml})$ were passed through the cartridges and cleaned up with $0.5 \mathrm{ml}$ of $40 \mathrm{mM}$ formic acid. The compounds retained were eluted directly into the LC column using the mobile phase for 20 minutes. Chromatographic separation was achieved using a Symmetry $C_{18}$ column $(250 \times 4.6 \mathrm{~mm} ; 5 \mu \mathrm{m}$; Waters), eluted at a constant flow rate of $1 \mathrm{ml} / \mathrm{min}$. The mobile phase consisted of (A) $40 \mathrm{mM}$ ammonium formiate containing $0.1 \%$ triethylamine $(\mathrm{pH} 4.5)$ and (B) acetonitrile as solvents. Samples were separated using a linear gradient from $10 \%$ to 
$55 \%$ B within 30 minutes. The mobile phase was returned to the starting solvent mixture in 1 minute and the system equilibrated for 8 minutes between runs. Incubation samples during LC analysis were always kept at $4^{\circ} \mathrm{C}$ in order to prevent aclidinium ester cleavage. Chromatographic data were processed using Millenium ${ }^{32}$ software, version 3.2 (Waters). The analytical method was validated for selectivity, linearity, quantitation limit, intra- and inter-batch precision and accuracy, recovery, and stability, demonstrating the suitability of this method for the quantitative measurements of test compounds and their respective metabolites.

\section{Method B}

Hepatocyte incubation samples were centrifuged for 10 minutes $\left(4^{\circ} \mathrm{C}\right)$ at $2,000 \mathrm{~g}$ and the supernatant was analyzed by LC with radiometric detection. Chromatographic separation was achieved using a Luna Phenyl-Hexyl column (250x4.6 mm; $5 \mu \mathrm{m}$; Phenomenex, Torrance, CA, USA) and eluted at a constant flow rate of $0.8 \mathrm{ml} / \mathrm{min}$. The mobile phase consisted of mixtures of (A) $1 \mathrm{M}$ ammonium acetate:water:acetonitrile (10:890:100, v/v/v) and (B) 1M ammonium acetate:water:acetonitrile (10:290:700, v/v/v). An initial proportion of 10\% B was maintained for 1 minute after sample injection ( $75 \mu \mathrm{l})$, followed by a linear gradient from $10 \%$ to $90 \%$ B within 7 minutes. B was maintained at $90 \%$ for 12 minutes and the mobile phase was returned to the starting solvent mixture in 1 minute. The system was equilibrated for 7 minutes between runs. All LC analysis samples were also kept at $+4^{\circ} \mathrm{C}$ in order to prevent aclidinium ester cleavage. Chromatographic data were processed as described above. 
The designation of the individual metabolites was coded to specify the structure and the origin of the biotransformation product. Thus, the initial letter refers to the parent compound origin: "M" metabolites formed from ${ }^{14} \mathrm{C}$-phe-AB and ${ }^{14} \mathrm{C}$-LAS34823 incubations, and " $m$ " metabolites formed from ${ }^{14} \mathrm{C}$-glyc-AB and ${ }^{14} \mathrm{C}$-LAS34850 incubations. The number given to a metabolite corresponds to a specific chemical entity identified according to the observed chromatographic retention time in the radiochromatograms. For example, metabolites M4 and m5 correspond to the same biotransformation product obtained in ${ }^{14} \mathrm{C}$-phe-AB or in ${ }^{14} \mathrm{C}$-glyc-AB incubations, respectively. Other minor LAS34823, LAS34850, and aclidinium metabolites were coded as $\mathrm{M} / \mathrm{m}$, followed by a lower-case subscript letter (eg: $\mathrm{M}_{\mathrm{f}}$ ). The identification of metabolites was based on comparison with standards and LC-MS/MS analysis.

\subsection{LC-MS and LC-MS/MS analysis}

The LC-MS system used for analysis of incubation supernatants consisted of an Agilent 1100 LC separation module (Waldbronn, Germany) coupled to an API Sciex 3000 triple quadrupole mass spectrometer (PerkinElmer, Boston, MA, USA). Chromatographic separation was achieved using a Symmetry $C_{18}$ column (100x2.6 $\mathrm{mm} ; 3.5 \mu \mathrm{m}$; Waters) with elution at a constant flow rate of $0.5 \mathrm{ml} / \mathrm{min}$. The mobile phase consisted of $10 \mathrm{mM} \mathrm{pH} 4.5$ ammonium formiate (A) and acetonitrile (B) as solvents. An initial proportion of $100 \%$ A was maintained for 2 minutes after sample injection, followed by a linear gradient from $0 \%$ to $45 \%$ B within 28 minutes. The mobile phase was returned to the starting solvent mixture in 1 minute, and the system was equilibrated for 7 minutes between runs. Mass spectrometry was conducted with electrospray ion source operating in positive ion mode $(A B$, 
LAS34823 and their metabolites) or negative ion mode (AB, LAS34850 and their metabolites). The ion spray interface temperature was set at $450^{\circ} \mathrm{C}$ (positive mode) and at $250^{\circ} \mathrm{C}$ (negative mode) using nitrogen as a nebulizing gas. LC/MS and LC/MS/MS experiments were performed at a voltage between 2.0-4.5 kV (positive mode) and $1.5 \mathrm{kV}$ (negative mode). The collision energy was between $30-45 \mathrm{eV}$ in positive mode and 5-30 eV in negative mode.

Metabolite identification was established by comparison with synthetic standards, when available, using retention time and mass spectral data.

\subsection{NMR analysis}

M1 (approximately $50 \mu \mathrm{g}$ ) isolated from an incubation of non-radiolabeled LAS34823 with rat and rabbit liver microsomes in the presence of NADPH was characterized using ${ }^{1} \mathrm{H}$ nuclear magnetic resonance (NMR). The ${ }^{1} \mathrm{H}$ NMR spectrum was recorded in a Varian Mercury-plus NMR spectrometer (Palo Alto, CA, USA) at $400 \mathrm{MHz}$. The sample was dissolved in deuterated DMSO- $d_{6}$. Chemical shifts were reported in the $\delta$ scale (ppm) by using DMSO- $\mathrm{d}_{6}$ signal at $2.49 \mathrm{ppm}$ as a reference.

\subsection{Statistics and data analysis}

Data from kinetic studies were analyzed by non-linear regression analysis with Grafit 5.0 (Erithacus Software, Staines, UK) using models for Michaelis-Menten kinetics, biphasic kinetics, or sigmoidal kinetics. In those cases where non-enzymatic hydrolysis occurred, the determination of the apparent Michaelis-Menten parameters 
$\left(\mathrm{K}_{\mathrm{m}}\right.$ and $\left.\mathrm{V}_{\max }\right)$ and non-enzymatic hydrolysis rate constant $\left(\mathrm{K}_{\mathrm{h}}\right)$ were carried out using the following equation [4]:

$$
v=\frac{V_{\max }[S]}{K_{m}+[S]}+K_{h}[S]
$$

where $v$ is the formation rate, $[S]$ is the substrate concentration, $K_{m}$ is the apparent Michaelis-Menten constant, $V_{\max }$ is the apparent maximum velocity, and $K_{h}$ is the non-enzymatic hydrolysis rate constant. The goodness-of-fit criteria used to select the model comprised visual inspection, consideration of the randomness of residuals, and the standard error of the parameters. 


\section{Results}

\subsection{Validation of the LC method with radiometric detection}

The oxidative and NADPH-dependent metabolites of ${ }^{14} \mathrm{C}$-phe-AB and ${ }^{14} \mathrm{C}$-glyc-AB were formed at a very low extent. Therefore, on-line SPE was necessary to improve the sensitivity of the radiometric detection method. To ensure the applicability of this method for the analysis of incubation samples, the method was fully validated for accuracy, precision, linearity, limit of quantitation, and compound stability. Overall, the analytical method demonstrated its suitability for the quantitative measurement of $\mathrm{AB}$ metabolites originated in vitro. The extraction recovery for test compounds and oxidative and hydrolysis metabolites ranged from $80 \%$ to $108 \%$. For each day of incubation, calibration standards $(n=5, r>0.995)$ and quality-control samples $(n=2$ at three different concentrations) of the corresponding radiolabeled test compounds were prepared in incubation buffer and treated as incubation samples. Intra- and inter-batch precision and accuracy of measurements of quality control samples, expressed as coefficient of variation, were always lower than $10 \%$ at all concentration levels. Following incubations of ${ }^{14} \mathrm{C}$-phe- $A B,{ }^{14} \mathrm{C}$-glyc- $A B,{ }^{14} \mathrm{C}$ LAS34823, and ${ }^{14} \mathrm{C}$-LAS34850 in human liver microsomes in the presence of $\mathrm{NADPH}$, the supernatant recoveries based on total radioactivity peak area (sum of peak areas of all metabolites and remaining parent compound) were, in all cases, greater than $85 \%$ with respect the radioactivity peak area of the test compound in control incubations. All test compounds were shown to be stable during the sample analysis. 


\subsection{Metabolism of aclidinium bromide in liver microsomes}

Incubations of ${ }^{14} \mathrm{C}$-phe-AB and ${ }^{14} \mathrm{C}$-glyc-AB in liver microsomes ( $0.5 \mathrm{mg}$ protein $/ \mathrm{ml}$ ) of animal species and humans were conducted at a concentration of $50 \mu \mathrm{M}$ in order to detect minor metabolites formed during incubations. Both radiolabeled forms of $A B$ were incubated for 60 minutes in order to evaluate differences in their metabolism. Aclidinium was shown to be an unstable ester in the incubation buffer $\left(\mathrm{pH}\right.$ 7.4). A species comparison of the overall metabolism of ${ }^{14} \mathrm{C}-\mathrm{phe}-\mathrm{AB}$ after 60 minutes of incubation is represented in Figure 2. The hydrolysis half-life in the assay buffer $\left(\mathrm{pH} 7.4,37^{\circ} \mathrm{C}\right)$ was around 70 minutes. The in vitro disappearance half-life of ${ }^{14} \mathrm{C}$-phe-AB in the absence of NADPH followed the rank order rat (male, female), 100 $\min \approx$ human, $93 \min >$ mouse (male), $42 \min \approx$ mouse (female), $37 \min >\operatorname{dog} 19$ $\min \approx$ rabbit, $16 \mathrm{~min}$. The results obtained following incubation of ${ }^{14} \mathrm{C}$-glyc-AB were similar to those obtained with ${ }^{14} \mathrm{C}$-phe-AB. Possible metabolites other than the hydrolysis metabolites (LAS34823 and LAS34850) were not observed in incubations without NADPH, suggesting that the oxidative metabolism of $A B$ in liver microsomes is primarily mediated by $\mathrm{P} 450$.

According to these results, enzymatic hydrolysis of aclidinium in human and rat liver microsomes was not observed, suggesting that the potential presence of esterases responsible for $A B$ hydrolysis in the microsomal fractions of these two species has little relevance. To confirm this, additional incubations of ${ }^{14} \mathrm{C}$-phe-LAS34273 (5 $\left.\mu \mathrm{M}\right)$ in human liver microsomes ( 1 and $2 \mathrm{mg} / \mathrm{ml}$ ) were investigated in the absence of NADPH and incubation buffer. There were slight differences in the formation of the hydrolysis metabolites between human liver microsomes and the incubation buffer. 
In fact, the net enzymatic hydrolysis of $A B$ at $2 \mathrm{mg} / \mathrm{ml}$ was less than $20 \%$ after 60 minutes of incubation. These results are in agreement with previous studies where BChE content was demonstrated to be low in human liver microsomes and consequently, the enzymatic hydrolysis of $A B$ had little scientific relevance compared to non-enzymatic hydrolysis [4].

Additional oxidative metabolism of aclidinium was observed in the presence of $\mathrm{NADPH}$. In this case, the in vitro disappearance half-life value for the overall metabolism of ${ }^{14} \mathrm{C}$-phe-AB followed the rank order rat (female), $73 \mathrm{~min}>$ rat (male), $56 \min \approx$ human, 52 min $>$ mouse (male, female), $23 \mathrm{~min}>$ dog $13 \mathrm{~min} \approx$ rabbit, 8 min. Similar values were also obtained for ${ }^{14} \mathrm{C}-$ glyc- $A B$.

The radioactive metabolite profiles of liver microsomal incubations of ${ }^{14} \mathrm{C}$-phe-AB and ${ }^{14} \mathrm{C}$-glyc-AB $(50 \mu \mathrm{M})$ with NADPH were qualitatively similar across species and representative chromatograms are shown in Figure 3. After incubation of ${ }^{14} \mathrm{C}$-pheAB, the major metabolite observed in all species was M2 (LAS34823, alcohol metabolite), whilst other minor and NADPH-dependent metabolites M1, M3, M4, M5, and M6 were also observed in different species. In the same way, the acid metabolite $\mathrm{m} 3$ (LAS34850) and metabolite $\mathrm{m} 2$ were the main metabolites in ${ }^{14} \mathrm{C}$-glyc$A B$ incubations. In addition, trace amounts of other metabolites $\left(m 1, m_{a}, m 4\right.$, and m5) were also observed in some species.

Incubation of ${ }^{14} \mathrm{C}$-LAS34823 with pooled human liver microsomes revealed the NADPH-dependent metabolism of this compound to metabolite M1 (Figure 3). 
Traces of other hydroxylated LAS34823 metabolites were also observed using MS/MS detection (Section 3.4.14).

After incubation of ${ }^{14} \mathrm{C}$-LAS34850 in incubation buffer, a radioactive peak was observed with a retention time of 31.5 minutes. The formation of this compound was independent of the incubation time and according to its chromatographic retention time and comparison of the MS spectra with a commercial standard, this artifact was identified as the compound di-2-thienyl ketone (see below). In the presence of $\mathrm{NADPH}$-generating system, the artifact disappeared and a new radioactive peak ( $\mathrm{t}_{\text {ret }}$ $19 \mathrm{~min}$ ) named $m_{a}$ was detected (Figure 3 ). The formation of $m_{a}$ was very rapid and did not increase with incubation time. Further investigations at different microsomal protein concentrations $(0.25,0.5$, and $1 \mathrm{mg} / \mathrm{ml})$ demonstrated that $\mathrm{m}_{\mathrm{a}}$ formation was non-enzymatic and dependent only on NADPH. This point was confirmed by performing additional incubations where the presence of $\mathrm{NADP}^{+}$(oxidized form) in buffer solution failed to generate $m_{a}$ (results not shown). The chemical structure of $\mathrm{m}_{\mathrm{a}}$ was tentatively elucidated by LC-MS/MS as the compound 2-dithienylacetic acid (see below). The presence of an acidic moiety in the chemical structure of $m_{a}$ was also confirmed by the chromatographic behaviour of this compound, increasing its retention time with increasing $\mathrm{pH}$ of the mobile phase in the same way observed for LAS34850. No other radioactive peaks were observed in the chromatograms, which suggests that enzymatic metabolism of LAS34850 does not occur.

The metabolites found in liver microsomal incubations of ${ }^{14} \mathrm{C}$-phe-AB and ${ }^{14} \mathrm{C}$-glyc$A B$ are summarized in Tables $\mathbf{1}$ and $\mathbf{2}$, respectively. 


\subsection{Metabolism of aclidinium bromide in hepatocytes}

The stability of $A B$ in Krebs-Henseleit incubation medium ( $\mathrm{pH}$ 7.4) showed an apparent elimination half-life $\left(\mathrm{t}_{1 / 2}\right)$ of 56 minutes, indicative of considerable nonenzymatic hydrolysis in the incubation conditions. The percentages of metabolism for ${ }^{14} \mathrm{C}$-phe-AB and ${ }^{14} \mathrm{C}$-glyc-AB were high in all species evaluated after two hours of incubation, ranging from $60 \%$ (human) to almost $100 \%$ (rabbit).

The major radioactive metabolites of ${ }^{14} \mathrm{C}$-phe-AB $(20 \mu \mathrm{M})$ in all species were $\mathrm{M} 2$ (LAS34823) and M1 (LAS188638). Representative chromatograms obtained in rabbit and human hepatocytes are shown in Figure 4. Rabbit hepatocytes showed the highest rate of $\mathrm{M} 1$ formation (around 50\%) and intermediate values (between 9 and $16 \%)$ were observed for mouse, rat and human hepatocytes. In contrast, dog hepatocytes showed the lowest formation of M1 (Table 1). Also, two polar radioactive metabolites were observed in mouse, rat, and rabbit hepatocytes. Their structures were identified by LC-MS/MS as the glucuronide conjugates of M1 and $M 2$, i.e., $M 1_{\text {gluc }}$ and $M 2_{\text {gluc }}$, respectively (see below). Rabbit hepatocytes produced the highest amount of glucuronide conjugates. Although M1 and M2 were generated to a similar extent in incubations, $\mathrm{M} 2_{\text {gluc }}$ was formed at much lower levels than $\mathrm{M} 1_{\text {gluc }}$. Thus, it is reasonable to propose that M1 glucuronidation occurs at the hydroxyl moiety located at the para position of the phenyl ring.

The major radioactive metabolite of ${ }^{14} \mathrm{C}$-glyc-AB $(20 \mu \mathrm{M})$ in all species was $\mathrm{m} 3$ (LAS34850), which accounted for $85 \%, 51 \%, 100 \%, 72 \%$, and $64 \%$ in mouse, rat, rabbit, dog, and human hepatocytes, respectively. Two minor polar metabolites were 
also observed in mouse, rat, and dog cryopreserved hepatocytes. One of these minor metabolites was identified as 2-thiopheneglyoxylic acid (m2), accounting for $1 \%-7 \%$ of total radioactivity. Metabolite $m_{x}$ was only observed in mouse, rat, and dog hepatocytes at a very low concentration (Table 2).

Metabolite $\mathrm{m} 2$ was only observed in ${ }^{14} \mathrm{C}$-glyc-AB incubations and not in ${ }^{14} \mathrm{C}$-phe- $\mathrm{AB}$ incubations (Table 2, Figure 3), which supports the hypothesis that the metabolic attack took place at the thiopheneglyoxylic moiety of the molecule. Nevertheless, this metabolite was not observed following incubation of ${ }^{14} \mathrm{C}$-LAS34850, suggesting that $\mathrm{m} 2$ might originate from the parent compound only.

Following incubation of ${ }^{14} \mathrm{C}$-LAS34823 $(20 \mu \mathrm{M})$ with human hepatocytes, only M1 (LAS188638) was observed, accounting for $28 \%$ of the radioactivity after an incubation time of 2 hours. The acid metabolite ${ }^{14} \mathrm{C}$-LAS34850 $(20 \mu \mathrm{M})$ was not metabolized by human hepatocytes during the two hours of incubation (Figure 4).

\subsection{Metabolite identification}

The identification of metabolites was based on comparison with standards (when available), LC-MS/MS and ${ }^{1} \mathrm{H}$ NMR. Metabolite identification was conducted by using LC-ESI-MS/MS in either positive or negative mode depending on the compound or metabolite of interest. 


\subsubsection{Aclidinium bromide}

The MS/MS spectrum of aclidinium in positive mode gave a major fragment ion at $\mathrm{m} / \mathrm{z} 262$, corresponding to the molecular ion of the alcohol derivative LAS34823. This fragment ion $m / z 262$ led to the sequential loss of $\mathrm{H}_{2} \mathrm{O}\left(\mathrm{m} / \mathrm{z}\right.$ 244) and $\mathrm{H}_{2} \mathrm{C}=\mathrm{CH}_{2}$ $(\mathrm{m} / \mathrm{z} 216)$ as shown in Figure 5A. This fragmentation pattern is in accordance with the MS/MS fragmentation of different $\mathrm{N}$-alkyl derivatives of 3-quinuclidinol molecules described by Bednár et al. [7].

\subsubsection{Metabolite M2 (LAS34823)}

LC-MS analysis of LAS34823 using ESI in positive mode showed a molecular ion $\left[\mathrm{M}^{+}\right]$of $\mathrm{m} / \mathrm{z} 262$. The product ion spectrum showed a fragment ion of $\mathrm{m} / \mathrm{z} 140$ as the most abundant. The fragment ions observed at $\mathrm{m} / \mathrm{z} 168$ and 107 suggest the loss of the phenoxymethyl moiety. The fragment of $m / z 135$ points to the loss of the phenoxypropyl moiety (Figure 5B).

\subsubsection{Metabolite M1 (LAS188638)}

This metabolite presented a molecular ion $\left[\mathrm{M}^{+}\right]$at $m / z 278$. The fragments obtained at $m / z 168,140$, and 124 were also observed in the spectrum of M2 (LAS34823), which suggests that the 3-quinuclidinol moiety remains unchanged. The observed fragments at $m / z 123(107+16 \mathrm{amu})$ and $151(135+16 \mathrm{amu})$ clearly suggest hydroxylation at the phenyl ring (Figure $\mathbf{5 C}$ ). In order to determine the exact position of hydroxylation, this metabolite was isolated and purified from rat and rabbit liver 
microsomal incubations for further analysis by ${ }^{1} \mathrm{H}$ NMR. The integrals of the aromatic region revealed that the point of hydroxylation was at the 4-position, since the spectrum showed two doublets (at a proportion 1:1) with a coupling constant of $\mathrm{J}=8$ $\mathrm{Hz}$. This was later confirmed with the synthesis of the authentic standard. The LCMS/MS analysis showed the same chromatographic retention time and mass fragmentation for both M1 and the authentic standard (LAS188638).

\subsubsection{Metabolites $M 1_{\text {gluc }}$ and $M 2_{\text {gluc }}$}

The formation of these conjugated metabolites was observed in hepatocyte incubations of ${ }^{14} \mathrm{C}$-Phe-AB, and their identification was conducted using the LCMS/MS in multiple reaction monitoring (MRM) mode. The theoretical transitions corresponding to the loss of the glucuronic acid moiety (176 Da) of the potential glucuronides of M1 and M2 $(\mathrm{m} / \mathrm{z} 454>278$ and $\mathrm{m} / \mathrm{z} 438>262$, respectively) were monitored. The radioactive peak with a retention time of 4.4 min showed a peak at the MRM transition of $m / z 454>278$, which corresponds to a glucuronide of M1. Similarly, the radioactive peak observed at 5.1 minutes presented a peak at the transition $\mathrm{m} / \mathrm{z} 438>262$, which strongly suggests the formation of a glucuronide derivative of metabolite M2. Additional incubations of rabbit and mouse hepatocyte samples with $\beta$-glucuronidase from Helix Pomatia demonstrated a decrease in the radioactive peak areas, although both glucuronide metabolites were highly resistant to enzymatic hydrolysis (results not shown).

\subsubsection{Metabolite $m 3$ (LAS34850)}


This compound presented two major peaks at $m / z 239$ and $m / z 195$ in negative ESI mode (Table 3). The fragment of $m / z 239$ corresponds to the molecular ion $[\mathrm{M}-\mathrm{H}]$;, whereas the fragment $m / z 195$ may be assigned to decarboxylation (in source collision-induced dissociation) of the molecular ion [8]. Additionally, a minor ion at $\mathrm{m} / \mathrm{z} 285$ was consistent with the formation of an adduct with the formate present in the mobile phase $[\mathrm{M}+\mathrm{HCOO}]^{-}$, a common process described in the literature $[9,10]$. The product ion mass spectrum of $m / z 239$ gave only the fragment of $m / z 195$, suggesting the loss of $\mathrm{CO}_{2}$ from the carboxylic acid group. The mass fragmentation of the product ion of $m / z 195$ gave a main fragment ion at $m / z 83$, which is in accordance with the loss of a thiophene ring.

\subsubsection{Metabolite $m 1$ (LAS101563)}

MS/MS (negative mode) characterization showed the molecular ion at $m / z 157$ and a peak at $\mathrm{m} / \mathrm{z} 113$ (Table 3). Moreover, a formate adduct was also observed in the MS spectrum $(157+46)$, confirming the presence of a carboxylic acid moiety in its structure, as observed for LAS34850 and m2. The chromatographic retention time and the mass fragmentation were identical to those of the authentic standard LAS101563 (hydroxyl-2-thienylacetic acid).

\subsubsection{Metabolite m2 (2-thiopheneglyoxylic acid)}

The MS (negative mode) spectrum showed a molecular ion at $m / z 155$. The peak observed at $\mathrm{m} / \mathrm{z} 201$ would be also compatible with the formation of an adduct with formic acid (Table 3). Further MS/MS characterization gave a single fragment at $\mathrm{m} / \mathrm{z}$ 
83, corresponding to the thiophene ring. The MS analysis showed the same chromatographic retention time and mass fragmentation of the authentic standard 2thiopheneglyoxylic acid.

\subsubsection{Metabolite $m_{a}$ (LAS101565)}

The full scan spectrum (negative mode) presented peaks at $\mathrm{m} / \mathrm{z} 269, \mathrm{~m} / \mathrm{z} 223$, and $\mathrm{m} / \mathrm{z} 179$ (Table 3). The peak of $m / z 223$ corresponds to the molecular ion [M-H]'. The peak observed at $m / z 269$ is compatible with the formation of a formate adduct, which was confirmed by further MS/MS analysis. The fragment of $\mathrm{m} / \mathrm{z} 195$ may be assigned to the decarboxylation of the molecular ion, in analogy to LAS34850 and other acidic metabolites. Product ion spectrum of $\mathrm{m} / \mathrm{z} 179$ showed abundant ions at $m / z 178,146,133,107$, and 83 . The LC-MS analysis showed the same chromatographic retention time of the authentic standard LAS101565.

\subsubsection{LAS34850 artifact}

In incubations of ${ }^{14} \mathrm{C}$-LAS34850 in phosphate buffer, a radioactive chromatographic peak appeared at a retention time of 31.4 minutes (Figure 3), which was associated with a degradation product or artifact of LAS34850. The commercially available compound dithienyl-2-ketone presented the same retention time and identical UV spectrum with a $\lambda_{\max }$ at $315 \mathrm{~nm}$. Further analysis using the LC-MS/MS method confirmed identical retention times (26.6 minutes) and identical mass fragmentation pattern in positive ESI mode (molecular ion at $\mathrm{m} / \mathrm{z}$ 195). Product ion scan of $\mathrm{m} / \mathrm{z} 195$ 
showed a fragment at $m / z 111$, corresponding to the loss of one thiophene ring. This compound was not ionizable in negative ESI mode.

\subsubsection{Metabolite $M 3 / m 4$}

The MS/MS (positive mode) of the molecular ion of $\mathrm{m} / \mathrm{z} 402$ presented major fragments at $m / z 262$ and 216, corresponding to the intact quinuclidinol portion of the molecule. These intact fragments indicate that the biotransformation occurs at the thiopheneglyoxylic acid moiety of the molecule. The product ion spectrum showed fragments at $m / z 308$ and $m / z 280$, which suggests that a thiophene ring has been removed from the structure, corresponding to a net loss of $82 \mathrm{Da}$ (Figure 6A).

\subsubsection{Metabolite $\mathrm{M} 4 / \mathrm{m5}$}

This metabolite presented an ion mass spectrum of $m / z 500$, which is 16 Da higher than that of the parent compound. The most prominent fragment $(\mathrm{m} / \mathrm{z} 278)$ pointed to a hydroxylation occurring at the quinuclidinol portion of the molecule. The presence of the minor fragments of $\mathrm{m} / \mathrm{z} 140,362$, and 390 suggested that the hydroxylation took place at the phenyl ring in a manner similar to that observed in the formation of M1 (Figure 6B). To confirm this hypothesis, an M4-purified sample obtained from incubations in liver microsomes was subjected to basic hydrolysis in order to generate the alcohol derivative of this metabolite, which matched the retention time and MS/MS spectrum of M1. 


\subsubsection{Metabolites $M 5 / m 6$ and $M 6 / m 7$}

Metabolites $\mathrm{M} 5 / \mathrm{m} 6$ and $\mathrm{M} 6 / \mathrm{m} 7$ were obtained in very low quantities and the chromatographic resolution was poor. These two metabolites presented a molecular ion of $m / z 500$ which is consistent with oxidation of the parent compound. In both cases, the MS/MS spectra showed a fragment of $m / z 262$, which is characteristic of an intact quinuclidinol moiety. In addition, a fragment of $\mathrm{m} / \mathrm{z} 401$ clearly points out to an oxidation at one of the thiophene rings. Nonetheless, the MS/MS spectra did not provide sufficient information to distinguish between C-oxidation (hydroxylation) and S-oxidation.

\subsubsection{Metabolite $m_{x}$}

This polar compund was present as a minor metabolite in incubations of ${ }^{14} \mathrm{C}$-glyc-AB in mouse, rat, and dog hepatocytes, although the low amounts prevented its characterization by LC-MS/MS.

\subsubsection{Other minor metabolites}

Additionally, other minor metabolites were detected by LC-MS but were below the level of radiometric detection. Four minor metabolites $\left(M_{a}, M_{b}, M_{c}\right.$, and $\left.M_{d}\right)$ with a molecular ion at $m / z 278$ were observed in AB and LAS34823 incubations. The MS spectra of two of them $\left(M_{a}\right.$ and $\left.M_{b}\right)$ confirmed the hydroxylation on the phenyl ring of LAS34823, hence constituting a positional isomer of $M 1 . M_{c}$ presented a mass fragmentation pattern different from M1, with a clear loss of water and the 
appearance of an ion at $m / z 156(140+16)$ as the major fragment ion, suggesting that hydroxylation would take place at the 3-quinuclidinol group. Supporting this hypothesis, the fragments at $m / z 107$ and 135 remained unchanged. $M_{d}$ characterization was not possible due to its low concentration. Metabolite $\mathrm{M}_{\mathrm{e}}$ presented a molecular ion $m / z 408$ and a major fragment of $186 \mathrm{Da}$, which is $76 \mathrm{Da}$ less than the major fragment $(\mathrm{m} / \mathrm{z} 262)$ of LAS34823, consistent with the loss of the phenyl ring. Another metabolite presented a molecular ion of $m / z 400\left(\mathrm{M}_{\mathrm{f}}, \mathrm{t}_{\mathrm{ret}} 23.8\right.$ $\mathrm{min})$. This molecular ion and the fragments at $m / z 152,135,124$, and 107 suggested that the quinuclidinol portion of the molecule remained intact. This fact implies that the biotransformation should take place at one of the thiophene rings, in a similar way already observed for $\mathrm{M} 3 / \mathrm{m} 4$, with the final loss of a thiophene ring. The presence of a fragment of $\mathrm{m} / \mathrm{z} 111$ strongly suggests oxidation of the alcohol moiety of $\mathrm{M} 3 / \mathrm{m} 4$ to a ketone derivative. In addition, other minor glucuronide metabolites in rat and mouse hepatocytes were also observed in LC-MS/MS (MRM mode) analysis using the transition $\mathrm{m} / \mathrm{z} 454>278$, consistent with structural isomers of $\mathrm{M} 1_{\text {gluc. }}$.

\subsection{Enzyme kinetics}

The enzyme kinetics of ${ }^{14} \mathrm{C}$-LAS34823, ${ }^{14} \mathrm{C}$-LAS34850, ${ }^{14} \mathrm{C}$-phe-AB, and ${ }^{14} \mathrm{C}$-glyc-AB metabolism in human liver microsomes was determined. The metabolites formed in incubations were quantified by LC with radiometric detection (method A) as described in Section 2.7. 
3.5.1. Kinetics of enzymatic metabolism of ${ }^{14} C$-LAS34823 and ${ }^{14} C$-LAS34850 enzyme kinetics

The kinetics of ${ }^{14} \mathrm{C}$-LAS34823 metabolism was investigated in pooled human liver microsomes over the concentration range 0.5 to $500 \mu \mathrm{M}$. A single radioactive metabolite M1 was observed in all the radiochromatograms (Figure 3). The kinetic profile of M1 formation exhibited substrate inhibition at LAS34823 concentrations greater than $100 \mu \mathrm{M}$, indicating that LAS34823 may inhibit its own metabolism (Figure 7A). Unfortunately, experimental data could not be fitted to any substrate inhibition model due to the severity of the inhibition. Within LAS34823 concentration range between 2 and $100 \mu \mathrm{M}$, the Eadie-Hofstee plot of the kinetic data obtained exhibited a biphasic pattern, suggesting that two enzymes of different affinity could be involved in the formation of M1 (Figure 7A). Although limited experimental data were available, data fitting was carried out assuming a bi-enzymatic MichaelisMenten model within this concentration range. The high-affinity component exhibited apparent $K_{\mathrm{m} 1}$ and $V_{\max 1}$ values of $2.1 \mu \mathrm{M}$ and $20.1 \mathrm{pmol} / \mathrm{min} / \mathrm{mg}$ protein, respectively. The low-affinity component exhibited apparent $K_{\mathrm{m} 2}$ and $V_{\max 2}$ values of $65.5 \mu \mathrm{M}$ and $192.7 \mathrm{pmol} / \mathrm{min} / \mathrm{mg}$ protein, respectively. The catalytic efficiency $\left(\mathrm{V}_{\mathrm{max}} / \mathrm{K}_{\mathrm{m}}\right)$ of the high-affinity component was approximately three-fold higher than that observed for the low-affinity component (Table 4).

On the other hand, following incubations of ${ }^{14} \mathrm{C}$-LAS34850 with liver microsomes, the formation of the radioactive peak $m_{a}$ was observed in phosphate buffer and liver microsomes only in the presence of NADPH-generating system or reduced NADPH, but not with $\mathrm{NADP}^{+}$(oxidized form). The fact that liver microsomal protein was not 
essential for $m_{a}$ formation strongly suggests a non-enzymatic reaction. Furthermore, the kinetics of ${ }^{14} \mathrm{C}$-LAS34850 metabolism were investigated in pooled human liver microsomes over the concentration range 0.5 to $500 \mu \mathrm{M}$ in the presence of NADPHgenerating system. No other LAS34850 metabolites apart from $m_{a}$ were observed at any concentration and the time course of $m_{a}$ formation was linear with increasing LAS34850 concentrations, confirming that its formation was non-enzymatic and only NADPH-dependent (Figure 7B).

\subsubsection{Kinetics of enzymatic metabolism of ${ }^{14} C-p h e-A B$}

The esterase-mediated hydrolysis of ${ }^{14} \mathrm{C}$-phe-AB $(5 \mu \mathrm{M})$ in human liver microsomes (1 and $2 \mathrm{mg} / \mathrm{ml}$ ) was investigated in the absence of NADPH. Parallel incubations in buffer ( $\mathrm{pH}$ 7.4) were also carried out as a control of non-enzymatic hydrolysis. There were slight differences in the formation of LAS34823 between human liver microsomes and the incubation buffer. In fact, the net enzymatic hydrolysis of aclidinium at a microsomal protein concentration of $2 \mathrm{mg} / \mathrm{ml}$ was less than $20 \%$ after 60 minutes of incubation. These results suggest that the esterase(s) responsible for the aclidinium hydrolysis have low catalytic activity in human liver microsomes.

In terms of substrate depletion, the rapid non-enzymatic hydrolysis of aclidinium compromised the selection of the incubation time for further kinetic studies. Incubation times of above 15 minutes led to a substrate depletion higher than $20 \%$. Moreover, at the highest protein concentration assayed $(1 \mathrm{mg} / \mathrm{ml})$ and incubation times of 15 and 30 minutes, aclidinium disappearance was also considerable due to the enzymatic formation of the oxidative metabolites M3 and M4. As a compromise, 
an incubation time of 15 minutes and $0.25 \mathrm{mg}$ of microsomal protein $/ \mathrm{ml}$ was selected.

The inhibitory potential of the main hydrolysis metabolites towards human esterases was of low relevance [4]. In addition, human CYP1A2, 2A6, 2C8, 2C9, 2C19, 2D6, 2E1, 3A4/5, and A9/11 activities were not inhibited by LAS34850 in vitro, whereas CYP2D6 was inhibited competitively by LAS34823 with an inhibition constant of 15.5 $\mu \mathrm{M}$ [11]. Thus, taking into account all these data, any potential interference of the hydrolysis metabolites on the characterization of the kinetics of ${ }^{14} \mathrm{C}$-phe-AB and ${ }^{14} \mathrm{C}$ glyc-AB is very unlikely.

The kinetics of ${ }^{14} \mathrm{C}$-phe-AB metabolism was investigated in pooled human liver microsomes over the concentration range 0.5 to $100 \mu \mathrm{M}$. In parallel, ${ }^{14} \mathrm{C}$-phe-AB was also incubated in phosphate buffer and with human liver microsomes without $\mathrm{NADPH}$-generating system. The $\mathrm{K}_{\mathrm{h}}$ in the incubation buffer was calculated from the slope of the regression line $\left(r^{2}=0.9991\right)$ and presented a value of $0.014 \mathrm{~min}^{-1}$ (Table 4). The major metabolite was M2 (LAS34823) and following inspection of the EadieHofstee plot obtained in human liver microsomes, two different phases could clearly be differentiated (Figure 8A). At low aclidinium concentrations, enzymatic hydrolysis may occur via esterases, and it was assumed that this process could be well described using the typical Michaelis-Menten equation. However, non-enzymatic hydrolysis becomes predominant at high substrate concentrations, leading to a constant value of the $\mathrm{v} /[\mathrm{S}]$ ratio, which is represented by the non-enzymatic hydrolysis rate constant $\left(\mathrm{K}_{\mathrm{h}}\right)$. The kinetic parameters were calculated using the mixed model described above (Section 2.10). The formation of M2 (LAS34823) 
without NADPH exhibited apparent $K_{m}$ and $V_{\max }$ values of $0.43 \mu \mathrm{M}$ and 37.7 $\mathrm{pmol} / \mathrm{min} / \mathrm{mg}$ protein, respectively. In contrast, higher apparent $\mathrm{K}_{\mathrm{m}}$ and $\mathrm{V}_{\max }$ values (1.78 $\mu \mathrm{M}$ and $253.9 \mathrm{pmol} / \mathrm{min} / \mathrm{mg}$ protein, respectively) were obtained in the presence of NADPH. The apparent $K_{h}$ values of ${ }^{14} \mathrm{C}$-phe-AB in human liver microsomes with and without NADPH were $0.012 \mathrm{~min}^{-1}$ and $0.010 \mathrm{~min}^{-1}$, respectively. The calculated intrinsic clearance $\left(\mathrm{V}_{\max } / \mathrm{K}_{\mathrm{m}}\right)$ with and without NADPH was 87.7 and $142.8 \mu \mathrm{l} / \mathrm{min} / \mathrm{mg}$ protein, respectively, which is consistent with an additional NADPHdependent metabolism of $A B$ apart from enzymatic hydrolysis.

The formation of the minor metabolites M3 and M4 was only observed in the presence of human liver microsomes and NADPH-generating system, confirming that their formation was enzymatic and NADPH-dependent. The kinetics of the formation of metabolites M3 and M4 followed the Michaelis-Menten model (Figure 8B). The formation of $\mathrm{M} 3$ exhibited apparent $\mathrm{K}_{\mathrm{m}}$ and $\mathrm{V}_{\max }$ values of $22.6 \mu \mathrm{M}$ and $283.4 \mathrm{pmol} / \mathrm{min} / \mathrm{mg}$ protein, respectively. The formation of $\mathrm{M} 4$ exhibited apparent $\mathrm{K}_{\mathrm{m}}$ and $\mathrm{V}_{\max }$ values of $4.6 \mu \mathrm{M}$ and $106 \mathrm{pmol} / \mathrm{min} / \mathrm{mg}$ protein, respectively. The enzymatic intrinsic clearance values $\left(\mathrm{Cl}_{\mathrm{int}}\right)$ for $\mathrm{M} 3$ and $\mathrm{M} 4$ were 12.5 and $23.0 \mu \mathrm{l} / \mathrm{mg}$ protein/min, respectively (Table 4).

\subsubsection{Kinetics of enzymatic metabolism of ${ }^{14} C$-glyc- $A B$}

The formation of ${ }^{14} \mathrm{C}$-glyc-AB metabolites in human liver microsomes was conducted in the incubation conditions established for ${ }^{14} \mathrm{C}$-phe-AB. Parallel incubations were also conducted in the incubation buffer as a control of non-enzymatic hydrolysis. The principal metabolite was the hydrolysis metabolite m3 (LAS34850) and was 
generated non-enzymatically as described above. Thus, m3 formation was linear in incubation buffer and a similar profile was also obtained in liver microsomes without NADPH. Interestingly, m3 (LAS34850) formation was lower after incubation in human liver microsomes with NADPH. This was a general observation for all concentrations tested (Figure 9A). As an example, the rates of formation at $\mathrm{a}^{14} \mathrm{C}$ glyc-AB concentration of $5 \mu \mathrm{M}$ were $253 \mathrm{pmol} / \mathrm{min} / \mathrm{mg}$ protein and $171 \mathrm{pmol} / \mathrm{min} / \mathrm{mg}$ protein, without and with NADPH, respectively.

The formation of $\mathrm{m} 2$ in incubations with human liver microsomes and NADPH followed a clear biphasic kinetic profile, which is in agreement with the participation of at least two different processes in its formation (Figure 9B). Following visual inspection of the Eadie-Hofstee plot and the standard errors of calculated parameters, the profile was best fitted to a mixed model assuming non-enzymatic degradation as well as to an enzymatic process (Michaelis-Menten), as described above. Assuming this model, the apparent hydrolysis rate constant $K_{h}$ was very rapid $\left(0.022 \pm 0.002 \mathrm{~min}^{-1}\right)$, representing a half-life of 32 minutes. The apparent $\mathrm{K}_{\mathrm{m}}$ and $\mathrm{V}_{\max }$ were $0.40 \mu \mathrm{M}$ and $328.3 \mathrm{pmol} / \mathrm{mg}$ protein/min, respectively. The intrinsic clearance was calculated to be $812.5 \mu \mathrm{l} / \mathrm{min} / \mathrm{mg}$ protein. The formation of $\mathrm{m} 4$ was enzymatic and NADPH-dependent. Its formation followed Michaelis-Menten kinetics with $\mathrm{K}_{\mathrm{m}}$ and $\mathrm{V}_{\max }$ values of $18.3 \mu \mathrm{M}$ and $229.2 \mathrm{pmol} / \mathrm{min} / \mathrm{mg}$ protein, respectively, which are practically identical to those found for $\mathrm{M} 3$ after incubation of ${ }^{14} \mathrm{C}$-phe-AB, confirming that $\mathrm{M} 3$ and $\mathrm{m} 4$ are actually the same metabolite. The generation of metabolite m5 was also enzymatic and NADPH-dependent. The apparent MichaelisMenten parameters $\mathrm{K}_{\mathrm{m}}$ and $\mathrm{V}_{\max }$ were $5.8 \mu \mathrm{M}$ and $100.4 \mathrm{pmol} / \mathrm{min} / \mathrm{mg}$ protein, respectively, also similar to those found for M4 (Table 4). 
The formation of $m_{a}$ was only observed at high ${ }^{14} \mathrm{C}$-glyc-AB concentrations and required the presence of a NADPH-generating system, as already described for LAS34850. The formation of metabolites $\mathrm{m} 1$ and $\mathrm{m} 5$ was negligible, thus, precluding any attempt of identification.

\subsection{Identification of $\mathbf{P} 450$ isoforms responsible for the metabolism of ${ }^{14} \mathrm{C}$-phe- $A B$ and ${ }^{14} C$-glyc-AB}

The identification of the P450 enzymes responsible for the formation of the oxidative metabolites of ${ }^{14} \mathrm{C}$-LAS34823, ${ }^{14} \mathrm{C}$-LAS34850, ${ }^{14} \mathrm{C}$-phe-AB, and ${ }^{14} \mathrm{C}$-glyc-AB was conducted using three different approaches: (a) incubations of test compounds with commercially available human cDNA-expressed P450 and FMO isoenzymes, (b) effect of selective chemical inhibitors of P450 isoenzymes in human liver microsomes, and (c) effect of selective antibodies against P450 isoenzymes in human liver microsomes.

\subsubsection{Identification of $\mathrm{P} 450$ isoforms responsible for the ${ }^{14} \mathrm{C}$-LAS34823} metabolism

The incubations of ${ }^{14} \mathrm{C}$-LAS34823 with human recombinant P450 (25 pmol/ml) and FMO $(0.2 \mathrm{mg} / \mathrm{ml})$ isoforms were carried out at a LAS34823 concentration of $5 \mu \mathrm{M}$. The formation of M1 was catalyzed only by human recombinant CYP2D6 with practically complete conversion of LAS34823 into M1. Additional metabolites were not observed in the presence of other P450 isoforms or flavin-containing 
monooxygenases (FMO1, FMO3, and FMO5). The kinetic parameters of $\mathrm{M} 1$ formation in the presence of recombinant human CYP2D6 were determined, corrected by P450 content $(2 \mathrm{pmol} / \mathrm{ml})$ and incubation time (20 minutes), in order to ensure linear conditions and low substrate depletion. An important inhibitory effect on $\mathrm{M} 1$ formation was also observed at substrate concentrations above $5 \mu \mathrm{M}$ and complete inhibition was obtained at the highest LAS34823 concentrations assayed $(100-200 \mu \mathrm{M})$. Within the LAS34823 concentration range $0.5-5 \mu \mathrm{M}$, the formation of M1 by CYP2D6 followed Michaelis-Menten kinetics with apparent $K_{m}$ and $V_{\max }$ values of $4.9 \mu \mathrm{M}$ and $22.1 \mathrm{pmol} / \mathrm{min} / \mathrm{pmol} \mathrm{P} 450$, respectively. These results are in agreement with the high-affinity enzyme observed in human liver microsomes. Incubations at higher LAS 34823 concentrations to identify the possible low-affinity component observed in human liver microsomes were not conducted, as it was not considered relevant due to the low systemic LAS34823 concentrations $(<0.5 \mathrm{nM})$ observed in clinical practice [12]. Following incubation in the presence of different chemical and antibody inhibitors, the formation of M1 was strongly inhibited by quinidine (CYP2D6 inhibitor) and by the antibody against CYP2D6 (Table 5).

\subsubsection{Identification of $P 450$ isoforms responsible for the ${ }^{14} C$-phe-AB metabolism}

The incubation of ${ }^{14} \mathrm{C}$-phe-AB $(5 \mu \mathrm{M})$ with human P450 $(25 \mathrm{pmol} / \mathrm{ml})$ and FMO $(0.2$ $\mathrm{mg} / \mathrm{ml}$ ) isoforms revealed that the formation of M1 (hydroxylated LAS34823) and M4 was only catalyzed by CYP2D6. Remarkably, the rate of formation of M2 (LAS34823) was also higher with human rCYP2D6 (2.92 pmol/min/pmol CYP) compared to the other rCYP isoforms (1.3-1.5 $\mathrm{pmol} / \mathrm{min} / \mathrm{pmol} \mathrm{CYP})$. Unfortunately, metabolite M3 was not observed in the incubation samples at the assay 
concentrations. Therefore, further inhibition experiments with chemical P450 inhibitors and antibodies in liver microsomes were studied at a ${ }^{14} \mathrm{C}$-phe-AB concentration of $25 \mu \mathrm{M}$. At this concentration, the formation of M2 was slightly inhibited (28\%) by the presence of ketoconazole (CYP3A4 inhibitor) and the formation of M3 was decreased by ketoconazole and slightly by quinidine. The formation of M4 was catalyzed by human rCYP2D6 and totally blocked by quinidine in human liver microsomes. Interestingly, human CYP1A1, which appears to be expressed in human liver at low levels $[13,14]$, could be also involved in the formation of M4. This means that the oxidative metabolism in the human lungs from smokers could be increased, since smoking-induced elevated levels of CYP1A1 have been observed [15].

The remaining chemical inhibitors had no particular influence on ${ }^{14} \mathrm{C}$-phe-AB metabolism. These results were also confirmed in the studies conducted with selective P450 antibodies. M2 formation was slightly affected by the presence of anti-CYP3A4, whilst M3 and M4 formation were inhibited by CYP3A4 and CYP2D6 inhibitory antibodies, respectively (Table 5).

\subsubsection{Identification of $P 450$ isoforms responsible for the ${ }^{14} C$-glyc-AB metabolism}

Incubations of ${ }^{14} \mathrm{C}$-glyc-AB with recombinant human $\mathrm{P} 450$ isoforms (rP450) were conducted at two different substrate concentrations ( 5 and $25 \mu \mathrm{M}$ ), in order to monitor the metabolite formation adequately. Further studies on the effect of different P450 chemical inhibitors and antibodies were studied at a single ${ }^{14} \mathrm{C}$-glyc-AB concentration of $25 \mu \mathrm{M}$. The results of these studies are summarized in Table 5. 
The formation of the hydrolysis metabolite m3 (LAS34850) was similar for all rCYPs assayed and control incubations (approximately $12 \mathrm{pmol} / \mathrm{min} / \mathrm{pmol}$ CYP), except in the case of CYP2D6, where a slight reduction was observed $(9.5 \mathrm{pmol} / \mathrm{min} / \mathrm{pmol}$ CYP). Metabolite $\mathrm{m} 3$ formation was not significantly affected by any of the human P450 inhibitors and inhibitory antibodies, indicating that its formation was not P450dependent.

Metabolite $\mathrm{m} 1$ was not observed in the presence of any of the rCYP isoforms assayed, most probably because the formation of this metabolite is dependent on $\mathrm{m} 2$ and/or m4 concentrations, which were always low. Metabolite m2 was formed to a similar extent in insect control incubations and with most human rCYPs (approx. 0.38 and $1.00 \mathrm{pmol} / \mathrm{min} / \mathrm{pmol} \mathrm{CYP}$ at 5 and $25 \mu \mathrm{M}$, respectively), with the exception of human CYP2D6 $(1.02 \mathrm{pmol} / \mathrm{min} / \mathrm{pmol} \mathrm{CYP}$ at $5 \mu \mathrm{M}$ and $2.5 \mathrm{pmol} / \mathrm{min} / \mathrm{pmol} \mathrm{CYP}$ at $25 \mu \mathrm{M})$ and CYP3A4 (0.49 pmol/min/pmol CYP at $5 \mu \mathrm{M}$ and $1.40 \mathrm{pmol} / \mathrm{min} / \mathrm{pmol}$ CYP at $25 \mu \mathrm{M}$ ), suggesting that these enzymes may be involved in its formation. The formation of $\mathrm{m} 2$ was inhibited substantially by ketoconazole (CYP3A4 inhibitor) and slightly by quercetin (CYP2C8 inhibitor). Moreover, the formation of $\mathrm{m} 2$ in human liver microsomes was slightly affected by the presence of CYP3A4 antibodies. Metabolite $m_{a}$ was observed to a similar extent in incubations with insect control and human rP450 isoforms (from 0.8 to $1.3 \mathrm{pmol} / \mathrm{min} / \mathrm{pmol} \mathrm{CYP}$ ), which is in accordance with the formation of LAS34850 and further chemical reduction by NADPH, because this co-factor was always present in the incubations. The formation of metabolite $\mathrm{m} 4$ was not catalyzed by any human CYP isoform at the two different substrate concentrations, although these results should be taken with caution due to the 
similar retention times of metabolites $\mathrm{m} 4$ and $\mathrm{m}_{\mathrm{a}}$. Curiously, metabolite $\mathrm{m} 4$ was not observed in incubations with recombinant CYP isoforms at any of the concentrations of ${ }^{14} \mathrm{C}$-glyc-AB assayed. In contrast, $\mathrm{m} 4$ was detected in inhibition studies with human liver microsomes. In these studies, some degree of inhibition was observed in the presence of human CYP3A4 and 2D6 antibodies, although conclusive results could not be obtained due to the low activity observed.

The formation of the hydroxylated metabolite m5 (M4) was mainly catalyzed by CYP2D6 (1.08 pmol/min/pmol CYP at $25 \mu \mathrm{M})$, as observed in ${ }^{14} \mathrm{C}-$ phe-AB incubations. This metabolite was also formed to a lesser extent in the presence of enzyme CYP1A1 $(0.60 \mathrm{pmol} / \mathrm{min} / \mathrm{pmol} \mathrm{CYP}$ at $25 \mu \mathrm{M})$. CYP1A1 involvement in the formation of M4 was not observed after ${ }^{14} \mathrm{C}$-phe-AB incubation, most probably due to the low concentration assayed $(5 \mu \mathrm{M})$. Metabolite $\mathrm{m} 5$ formation in human liver microsomes was inhibited only by quinidine (CYP2D6 inhibitor) and human CYP2D6 antibodies, which is in agreement with the results obtained above (Table 5). 


\section{Discussion}

The non-enzymatic hydrolysis of aclidinium $(A B)$ observed in the incubation buffer (pH 7.4) was high and accounted for approximately $45 \%$ of overall metabolism in incubations conducted with liver microsomes. The rate of enzymatic hydrolysis of both radiolabeled forms, measured in the absence of NADPH, was higher in experimental systems of rabbit and dog followed by those mouse. Remarkably, the formation rate of the hydrolysis metabolites in rat and human liver microsomes was similar to that obtained in incubation, suggesting a low esterase activity in these liver subcellular fractions. This observation has already been done in a previous study using human liver microsomes [4].

The net oxidative metabolism obtained by subtraction of non-NADPH and NADPHdependent metabolism was similar across all species examined, but its extent was far lower compared to the hydrolysis process. In hepatocytes, the overall rate of aclidinium metabolism followed the rank order: rabbit $>$ mouse $>$ dog $>$ rat $\approx$ human. Although the enzymatic hydrolysis of aclidinium in hepatocytes cannot be differentiated from its overall metabolism, the metabolism pattern was similar to the obtained in liver microsomes.

The major radioactive metabolites of ${ }^{14} \mathrm{C}$-phe-AB and ${ }^{14} \mathrm{C}$-glyc-AB detected in liver microsomes and hepatocytes of all species were the alcohol and acid metabolites, M2 (LAS34823) and m3 (LAS34850), respectively. These two hydrolysis metabolites are devoid of in vitro antimuscarinic activity and show no relevant bronchodilatory activity in preclinical models [3]. 
The formation of M2 (LAS34823) was slightly higher in human liver microsomes with NADPH at low ${ }^{14} \mathrm{C}$-phe-AB concentrations. Inspection of Eadie-Hofstee plots confirmed the differentiation between enzymatic and non-enzymatic hydrolysis, as previously observed in human plasma. The slight inhibition of LAS34823 formation produced by ketoconazole and CYP3A4 antibody may be explained by the inhibition of the precursor metabolite $\mathrm{M} 3 / \mathrm{m} 4$, the formation of which was also mediated by CYP3A4. In contrast, m3 formation (LAS34850) was lower after incubation in human liver microsomes with NADPH, which could be related to the increased oxidative pathway of primary metabolites such as $\mathrm{M} 3 / \mathrm{m} 4$, whose hydrolysis leads to the formation of metabolites other than $\mathrm{m} 3$. On the other hand, $\mathrm{m} 3$ formation was similar with all recombinant CYPs assayed with the exception of CYP2D6, where small amounts were formed. This fact confirms that other metabolic routes involving the thiopheneglyoxylic moiety of aclidinium are in competition with the hydrolysis process.

Other major metabolites obtained in incubations of ${ }^{14} \mathrm{C}$-phe-AB and ${ }^{14} \mathrm{C}$-glyc-AB were identified as hydroxylated LAS34823 (M1) and 2-thiopheneglyoxylic acid (m2), respectively.

In humans, the formation of M1 from LAS34823 was catalyzed by CYP2D6 and a substrate inhibition profile was apparent at higher concentrations, which is in agreement with a previous in vitro study where this compound was shown to be a moderate inhibitor of the catalytic activity of human CYP2D6 with an apparent $\mathrm{K}_{\mathrm{i}}$ of $15 \mu \mathrm{M}$ [11]. Following incubation of $\mathrm{AB}$, the formation of $\mathrm{M} 1$ could be explained by 
two different routes: a) direct hydroxylation of the hydrolysis product LAS34823 (M2) and b) hydrolysis of metabolite $\mathrm{M} 4 / \mathrm{m} 5$.

The rapid generation of $\mathrm{m} 2$ in liver microsomes and hepatocytes is difficult to interpret. According to its chemical structure, the most plausible explanation for its formation is related to the primary oxidation of $\mathrm{m} 4 / \mathrm{M} 3$ and further hydrolysis, as represented in Figure 1. Indeed, the formation of $\mathrm{m} 2$ followed a biphasic kinetic profile in incubations with human liver microsomes and NADPH, consistent with the participation of two different processes (Figure 9B).

The apparent $\mathrm{K}_{\mathrm{h}}$ obtained for $\mathrm{m} 2$ was higher than that observed for the hydrolysis metabolite M2, suggesting a faster hydrolysis of its tentative primary metabolite $M_{f}$ into $\mathrm{m} 2$ and M2 (LAS34823). Furthermore, the enzymatic origin of $\mathrm{m} 2$ was demonstrated by its formation in the presence of rCYP2D6 and in lower amounts by rCYP3A4. The involvement of CYP2D6 and CYP3A4 was further confirmed by inhibition studies. The fact that $\mathrm{m} 2$ formation was more affected by CYP3A4 inhibitors could be explained by the relative content of these enzymes in the human liver, with average values of 30\% (CYP3A4) and 2.5\% (CYP2D6) of the total P450 content [16]. The slight inhibition caused by quercetin could be explained by its lack of selectivity as a CYP2C8 inhibitor, as described by Obach [17]. The low apparent $\mathrm{K}_{\mathrm{m}}$ and the high intrinsic clearance suggest that this metabolic pathway would be relevant in vivo.

The minor aclidinium metabolites $\mathrm{M} 3 / \mathrm{m} 4, \mathrm{M} 4 / \mathrm{m} 5, \mathrm{M} 5 / \mathrm{m} 6, \mathrm{M} 6 / \mathrm{m} 7$, and $\mathrm{m} 1$ accounted for less than $5 \%$ of total metabolism in liver microsomes and were not detected in 
hepatocytes, suggesting that these metabolites are actually intermediate metabolites that are likely to be further metabolized. As it was expected, the formation of these intermediate metabolites was similar following incubations of ${ }^{14} \mathrm{C}$-phe- $\mathrm{AB}$ and ${ }^{14} \mathrm{C}$ glyc-AB with liver microsomes. The origin of metabolite $M 3 / \mathrm{m} 4$ is an intriguing issue that cannot be completely addressed for the moment. However, the loss of a thiophene ring from aclidinium could be explained by thiophene oxidation (hydroxylation or S-oxidation) and further ring opening in a similar manner that has been described for compounds such as suprofen and tienilic acid [18]. This complex process would mean that the minor metabolites $\mathrm{M} 5 / \mathrm{m} 6$ and $\mathrm{M} 6 / \mathrm{m} 7$ could actually be precursors for the formation of $\mathrm{M} 3 / \mathrm{m} 4$. An interesting observation was that the primary metabolite $\mathrm{M} 3 / \mathrm{m} 4$ was generated to a greater extent than its oxidized metabolite $\mathrm{M}_{\mathrm{f}}$, which was only detected by MS detection. In contrast, the metabolite m2 (hydrolytic metabolite of $\mathrm{M}_{\mathrm{f}}$ ) was always formed to a greater extent than $\mathrm{m} 1$ (hydrolytic metabolite of $\mathrm{M} 3 / \mathrm{m} 4$ ), strongly supporting faster hydrolysis of the primary metabolite $\mathrm{M}_{\mathrm{f}}$ compared to $\mathrm{M} 3 / \mathrm{m} 4$. The formation of the $\mathrm{p}$-hydroxylated metabolite of aclidinium (M4/m5) was catalyzed by human CYP2D6, in analogy to the formation of M1. Metabolite m1 (hydroxyl-2-thienylacetic acid) was also observed at very low levels in liver microsomes of mouse, rabbit, and human, which could be associated with the hydrolysis of its primary metabolite $\mathrm{M} 3 / \mathrm{m} 4$. In this study, one of the minor metabolic routes identified involved the oxidation of the thiophene rings of aclidinium (M5/m6 and M6/m7). The formation of these metabolites could be related to the formation of potential reactive metabolites. However, the recovery of total radioactivity in the supernatans of incubations of ${ }^{14} \mathrm{C}$-phe-AB, ${ }^{14} \mathrm{C}$-glyc-AB, ${ }^{14} \mathrm{C}$ LAS34823, and ${ }^{14} \mathrm{C}$-LAS34850 in human liver microsomes was greater than $85 \%$, what suggests that this metabolic route would be a minor process. Additional 
investigations were also performed although the results of these studies are outside the scope of the current study.

The incubation of ${ }^{14} \mathrm{C}$-LAS34850 in human liver microsomes revealed some interesting features. An artifact was generated in the incubation buffer that was identified as the compound di-2-thienyl ketone. The biomimetic oxidative formation of a similar compound has been also described for denaverine hydrochloride [19]. The formation of metabolite $m_{a}$ was only observed in incubations where the NADPH (reduced form) was present with or without liver microsomes, which would be compatible with a non-enzymatic reduction process of the hydroxyl moiety by $\mathrm{NADPH}$. Furthermore, the formation of $m_{a}$ was linear with increasing LAS34850 concentrations, confirming that its formation was non-enzymatic. On the other hand, it is important to note that the polar metabolites $\mathrm{m} 1$ and $\mathrm{m} 2$ were not generated during the incubation of ${ }^{14} \mathrm{C}$-LAS34850 with human liver microsomes and hepatocytes. These observations confirm that these metabolites can be formed only from the parent compound but not from m3 (LAS34850), which is the main circulating metabolite in humans [12].

In summary, the present study indicates that aclidinium hydrolysis is the main biotransformation route in liver microsomes and hepatocytes of mouse, rat, rabbit, dog, and human, with rabbit and dog exhibiting the highest rates of enzymatic hydrolysis. Oxidative metabolism in liver microsomes and hepatocytes was substantially lower when compared to ester hydrolysis. The metabolite profiles were similar across all five species examined and up to five primary metabolites and eight secondary metabolites were characterized. The alcohol metabolite (LAS34823) is 
transformed to a single hydroxylated metabolite that is subsequently glucuronidated. In contrast, the acid metabolite (LAS34850) was not metabolized enzymatically in vitro. The oxidative conversion of $A B$ and its alcohol metabolite was primarily catalyzed by human CYP2D6 and CYP3A4.

\section{Acknowledgments}

We would like to acknowledge the technical support provided by Francisco Jimenez Berbell. We also thank Josep M. Huerta, Department of Computational and Structural Drug Discovery (Almirall, S.A.), for analyzing the ${ }^{1} \mathrm{H}$ NMR spectrum of metabolite M1. 


\section{References}

[1] Gavaldà A, Miralpeix M, Ramos I, Otal R, Carreño C, Viñals M, et al. Characterization of aclidinium bromide, a novel inhaled muscarinic antagonist, with long duration of action and a favorable pharmacological profile. $\mathrm{J}$ Pharmacol Exp Ther 2009; 331: 740-51.

[2] Prat M, Fernández D, Buil MA, Crespo MI, Casals G, Ferrer M, et al. Discovery of Novel Quaternary Ammonium Derivatives of (3R)-Quinuclidinol Esters as Potent and Long-acting Muscarinic Antagonists with Potential for Minimal Systemic Exposure after Inhaled Administration: Identification of (3R)3-\{[hydroxy(di-2-thienyl)acetyl]oxy\}-1-(3-phenoxypropyl)-1azoniabicyclo[2.2.2]octane bromide (Aclidinium Bromide). J Med Chem 2009; 52: 5076-92.

[3] Sentellas S, Ramos I, Albertí J, Salvà M, Antón F, Miralpeix M, et al. Aclidinium bromide, a new, long-acting, inhaled muscarinic antagonist: In vitro plasma inactivation and pharmacological activity of its main metabolites. Eur $\mathrm{J}$ Pharm Sci 2010; 39: 283-90.

[4] Albertí J, Martinet A, Sentellas S, Salvà M. Identification of the human enzymes responsible for the enzymatic hydrolysis of aclidinium bromide. Drug Metab Disp 2010; 38: 1202-10. 
[5] Placidi L, Scott EC, de Sousa G, Rahmani R, Placidi M, Sommadossi JP. Interspecies variability of TNP-470 metabolism, using primary monkey, rat, and dog cultured hepatocytes. Drug Metab Dispos 1997; 25: 94-9.

[6] Hewitt NJ, Fischer T, Zuehlke U, Oesch F, Utesch D. Metabolic activity of fresh and cryopreserved cynomolgus monkey (Macaca fascicularis) hepatocytes. Xenobiotica 2000; 30: 665-81.

[7] Bednár P, Lemr K, Barták P, Sevcík J, Hlavác J, Stýskala J, et al. Capillary electrophoresis/mass spectrometry: a promising tool for the control of some physiologically hazardous compounds. I-derivatives of 3-quinuclidinol. J Mass Spectrom 2002; 37: 1213-18.

[8] Pati S, Losito I, Palmisano F, Zambonin PG. Characterization of caffeic acid enzymatic oxidation by-products by liquid chromatography coupled to electrospray ionization tandem mass spectrometry. J Chromatogr A 2006; 1102: $184-92$.

[9] Ma YC, Kim HY. Determination of steroids by liquid chromatography/mass spectrometry. J Am Soc Mass Spectrom 1997; 8: 1010-20.

[10] Volmer DA, Hui JPM. Rapid determination of corticosteroids in urine by combined solid phase microextraction/liquid chromatography/mass spectrometry. Rapid Commun Mass Spectrom 1997; 11: 1926-33. 
[11] Almirall S.A., data on file.

[12] Jansat JM, Lamarca R, García-Gil E, Ferrer O. Safety and pharmacokinetics of single doses of aclidinium bromide, a novel long-acting, inhaled muscarinic, in healthy subjects. J Clin Pharmacol Ther 2009; 47: 460-8.

[13] Stiborová M, Martínek V, Rýdlová H, Hodek P, Frei E. Sudan I Is a Potential Carcinogen for Humans: Evidence for Its Metabolic Activation and etoxication by Human Recombinant Cytochrome P450 1A1 and Liver Microsomes. Cancer Res 2002; 62: 5678-5684.

[14] Drahushuk AT, McGarrigle BP, Larsen KE, Stegeman JJ, Olson JR. Detection of CYP1A1 protein in human liver and induction by TCDD in precision-cut liver slices incubated in dynamic organ culture. Carcinogenesis 1998;19:13611368

[15] Smith GBJ, Harper PA, Wong JMY, Lam MSM, Reid KR, Petsikas D, et al. Human Lung Microsomal Cytochrome P4501A1 (CYP1A1) Activities. Impact of Smoking Status and CYP1A1, Aryl Hydrocarbon Receptor, and Glutathione S-Transferase M1 Genetic Polymorphisms. Cancer Epidemiol Biomarkers Prev 2001; 10: 839-53.

[16] Rendic S, DiCarlo FJ. Human cythocrome P450 enzymes: a status report summarizing their reactions, substrates, inducers and inhibitors. Drug Metab Rev 1997; 29: 413-580. 
[17] Obach R. Inhibition of human cytochrome P450 enzymes by constituents of St. John's Wort, an herbal preparation used in the treatment of depression. $J$ Pharmacol Exp Ther 2000; 294: 88-95.

[18] O'Donnell JP, Dalvie DK, Kalgutkar AS, Obach RS. Mechanism-based inactivation of human recombinant P450 2C9 by the nonsteroidal antiinflammatory drug suprofen. Drug Metab Dispos 2003; 31: 1369-77.

[19] Smolinka K, Göber B. Biomimetic oxidation of denaverine hydrochloride. European J Org Chem 1999; 3: 679-83. 


\section{Figure captions}

FIG 1. Proposed in vitro metabolic pathways for aclidinium bromide in animal species and humans. Dashed arrows indicate possible paths of metabolite formation. Symbols * and \# denote the positions of ${ }^{14} \mathrm{C}$-labeled carbon atoms in ${ }^{14} \mathrm{C}$-phe- $\mathrm{AB}$ and ${ }^{14} \mathrm{C}$-glyc-AB, respectively. Metabolites generated from ${ }^{14} \mathrm{C}$-phe-AB incubations were coded as " $\mathrm{M}$ ", whereas metabolites generated from ${ }^{14} \mathrm{C}$-glyc-AB incubations were coded as " $m$ ".

FIG 2. Percentage of metabolism of $(A){ }^{14} \mathrm{C}$-phe- $A B(50 \mu \mathrm{M})$ after 60 minutes in incubation buffer and in liver microsomes of different species $(\mathrm{m})$ : male; $(\mathrm{f})$ : female; (mix): mixed gender. Each bar represents the mean of duplicate determinations ( $<15 \%$ variance).

FIG 3. Representative chromatograms (Method $A$ ) showing metabolite profiles of $50 \mu \mathrm{M}{ }^{14} \mathrm{C}$-phe-AB and ${ }^{14} \mathrm{C}$-phe- $A B$ in phosphate buffer $(A, B), 50 \mu M{ }^{14} C$-phe- $A B$ and ${ }^{14} \mathrm{C}$-glyc- $A B$ in human liver microsomes (HLM) with NADPH (C,D), $10 \mu \mathrm{M}{ }^{14} \mathrm{C}$-LAS34823 in human liver microsomes with NADPH (E), and $10 \mu \mathrm{M}{ }^{14} \mathrm{C}$-LAS34850 in phosphate buffer and human liver microsomes with/without NADPH.

FIG 4. Representative chromatograms (Method B) showing metabolite profiles of ${ }^{14} \mathrm{C}$-phe- $\mathrm{AB}$ and ${ }^{14} \mathrm{C}$ glyc-AB in human hepatocytes (A, B), ${ }^{14} \mathrm{C}$-phe-AB and ${ }^{14} \mathrm{C}$-glyc-AB in rabbit hepatocytes $(C, D),{ }^{14} \mathrm{C}$ LAS34823 and ${ }^{14}$ C-LAS34850 in human hepatocytes (E.F). Test substances were incubated at a final concentration of $20 \mu \mathrm{M}$.

FIG 5. MS/MS spectra of (A) aclidinium bromide, (B) metabolite M2 (LAS34823), and (C) metabolite M1 (LAS188638).

FIG 6. MS/MS spectra of (A) M3/m4 and (B) M4/m5 metabolites.

FIG. 7. Kinetics of (A) M1 formation from ${ }^{14} \mathrm{C}$-LAS34823, and (B) $m_{a}$ formation from ${ }^{14} \mathrm{C}$-LAS34850 in human liver microsomes. Symbols represent observed data (mean of duplicate determinations). Solid 
lines represent calculated rates with $(A)$ bi-enzymatic Michaelis-Menten equation in the range of concentration of 2-100 $\mu \mathrm{M}$ and $(\mathrm{B})$ linear regression.

FIG. 8. Eadie-Hofstee plots of (A) M2 formation from ${ }^{14} \mathrm{C}$-phe-AB with (filled diamonds) and without (open circles) NADPH and (B) M3 and M4 formation from ${ }^{14} \mathrm{C}$-phe-AB in human liver microsomes. Symbols represent observed data (mean of duplicate determinations); solid lines represent rates calculated by nonlinear regression.

FIG. 9. Formation of metabolite (A) $m 3$ (LAS34850) from ${ }^{14} \mathrm{C}$-glyc-AB in incubation buffer (filled triangles), human liver microsomes without NADPH, and human liver microsomes with NADPH. (B) Eadie-Hofstee plot of $\mathrm{m} 2$ from ${ }^{14} \mathrm{C}$-glyc-AB in human liver microsomes. Symbols represent observed data (mean of duplicate determinations); solid lines represent rates calculated by nonlinear regression. 


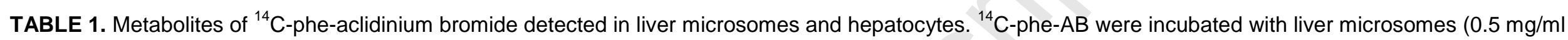
and NADPH-generating system) and hepatocytes (2 M cells $/ \mathrm{ml}$ ) for 60 and 120 minutes, respectively. Results expressed as percentage of total peak area of the radiochromatograms.

\begin{tabular}{|c|c|c|c|c|c|c|c|c|}
\hline Metabolite & $\mathrm{RT}$ & $\begin{array}{c}\text { Mouse } \\
\text { (m) }\end{array}$ & $\begin{array}{c}\text { Mouse } \\
\text { (f) }\end{array}$ & $\begin{array}{l}\text { Rat } \\
(\mathrm{m})\end{array}$ & $\begin{array}{l}\text { Rat } \\
\text { (f) }\end{array}$ & $\begin{array}{c}\text { Rabbit } \\
\text { (f) }\end{array}$ & $\begin{array}{l}\text { Dog } \\
(\mathrm{m})\end{array}$ & $\begin{array}{l}\text { Human } \\
\text { (mix) }\end{array}$ \\
\hline \multicolumn{9}{|c|}{ Liver microsomes } \\
\hline M1 & $6.2(8.8)$ & 3.7 & 3.5 & 7.1 & 4.3 & 8.2 & 9.3 & 0.9 \\
\hline M2 & $12.6(13.2)$ & 75.7 & 75.4 & 36.5 & 36.5 & 91.0 & 85.7 & 47.5 \\
\hline M3 & $19.9(20.2)$ & d & ND & ND & ND & $d$ & ND & 2.1 \\
\hline M4 & $21.8(22.4)$ & 1.1 & 1.3 & 2.0 & 1.1 & d & 0.9 & 2.5 \\
\hline M5 & $22.6(25.3)$ & d & 1.3 & 1.4 & ND & ND & ND & 0.7 \\
\hline M6 & $23.1(25.4)$ & 0.9 & 1.0 & 2.0 & ND & d & ND & 1.1 \\
\hline \multicolumn{9}{|c|}{ Hepatocytes } \\
\hline M1gluc & 3.9B (3.9) & 2.7 & - & 2.5 & - & 14.8 & ND & ND \\
\hline M2gluc & $4.4 \mathrm{~B}(4.4)$ & 0.5 & - & 0.6 & - & 1.4 & ND & ND \\
\hline M1 & $6.2(8.8)$ & 15.9 & - & 13.9 & - & 51.2 & 1.7 & 9.2 \\
\hline M2 & $12.6(13.2)$ & 73.1 & - & 59.5 & - & 32.6 & 87.3 & 76.2 \\
\hline
\end{tabular}

Mean values from duplicate (liver microsomes) and triplicate (hepatocytes) experiments

m, male; $f$, female; mix, mixed gender

$\mathrm{RT}$, retention time (minutes) using method A, if not otherwise indicated. In brackets, retention times using LC-MS/MS. 


\section{-: assay not performed}

$\mathrm{ND}$, not detected, below $0.5 \%$ of total radioactive peak area.

d, metabolite detected at shorter incubation times

Metabolites generated from ${ }^{14} \mathrm{C}$-phe-AB incubations were coded as "M". Metabolites M1gluc and M2gluc were not observed in microsomal incubation, whereas M3, M4, M5, and M6 were not observed in hepatocyte incubations. 
TABLE 2. Metabolites of ${ }^{14} \mathrm{C}$-glyc-aclidinium bromide detected in liver microsomes and hepatocytes. ${ }^{14} \mathrm{C}-\mathrm{glyc}$ - $\mathrm{AB}$ were incubated with liver microsomes $(0.5 \mathrm{mg} / \mathrm{ml}$ and NADPH-generating system) and hepatocytes (2 M cells $/ \mathrm{ml}$ ) for 60 and 120 minutes, respectively. Results expressed as percentage of total peak area of the radiochromatograms.

\begin{tabular}{|c|c|c|c|c|c|c|c|c|}
\hline Metabolite & RT & $\begin{array}{c}\text { Mouse } \\
\text { (m) }\end{array}$ & $\begin{array}{c}\text { Mouse } \\
\text { (f) }\end{array}$ & $\begin{array}{l}\text { Rat } \\
\text { (m) }\end{array}$ & $\begin{array}{l}\text { Rat } \\
\text { (f) }\end{array}$ & $\begin{array}{c}\text { Rabbit } \\
\text { (f) }\end{array}$ & $\begin{array}{l}\text { Dog } \\
(\mathrm{m})\end{array}$ & $\begin{array}{l}\text { Human } \\
\text { (mix) }\end{array}$ \\
\hline \multicolumn{9}{|c|}{ Liver microsomes } \\
\hline $\mathrm{m} 1$ & $4.4(1.5)$ & 3.1 & 2.3 & ND & ND & 1.8 & ND & 2.5 \\
\hline $\mathrm{m} 2$ & $5.1(3.0)$ & 23.5 & 29.9 & 15.5 & 9.6 & 19.5 & 16.3 & 13.7 \\
\hline m3 & $14.2(16.6)$ & 57.2 & 52.6 & 33.1 & 36.0 & 74.1 & 76.1 & 33.7 \\
\hline $\mathrm{m}_{\mathrm{a}}$ & $19.3(18.6)$ & 3.4 & 3.0 & 2.8 & 2.0 & 4.6 & 4.9 & 2.8 \\
\hline m4 (M3) & $19.9(20.2)$ & $d$ & ND & $d$ & ND & d & ND & 3.1 \\
\hline m5 (M4) & $21.8(22.4)$ & 1.2 & 1.3 & 1.7 & 0.9 & d & 1.4 & 3.3 \\
\hline m6 (M5) & $22.6(25.3)$ & ND & 1.0 & 1.0 & ND & ND & ND & ND \\
\hline m7 (M6) & $23.1(25.4)$ & ND & 0.9 & ND & 1.5 & ND & ND & ND \\
\hline \multicolumn{9}{|c|}{ Hepatocytes } \\
\hline$m_{x}$ & $3.5(\mathrm{ND})$ & 0.5 & - & 0.9 & - & ND & 0.8 & ND \\
\hline $\mathrm{m} 1$ & $4.4(1.5)$ & ND & - & ND & - & ND & ND & ND \\
\hline $\mathrm{m} 2$ & $5.1(3.0)$ & 1.4 & - & 6.7 & - & ND & 0.8 & ND \\
\hline m3 & $14.2(16.6)$ & 85.4 & - & 50.6 & - & 100 & 71.8 & 63.7 \\
\hline
\end{tabular}


ND

ND

ND

ND

Mean values from duplicate (liver microsomes) and triplicate (hepatocytes) experiments

m, male; f, female; mix, mixed gender

$\mathrm{RT}$, retention time (minutes) using method A, if not otherwise indicated. In brackets, retention times using LC-MS/MS.

-: assay not performed

ND, not detected, below $0.5 \%$ of total radioactive peak area.

$\mathrm{d}$, metabolite detected at shorter incubation times

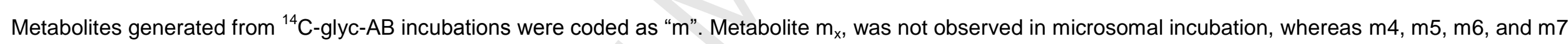
were not observed in hepatocyte incubations. 
TABLE 3. MS and MS/MS spectral data of ${ }^{14} \mathrm{C}$-glyc-AB metabolites.

1

\begin{tabular}{|c|c|c|c|}
\hline \multirow[b]{2}{*}{ Metabolite } & \multicolumn{2}{|c|}{ MS spectra } & \multirow{2}{*}{$\begin{array}{l}\text { MS/MS spectra } \\
\text { Relevant product ions }(\mathrm{m} / \mathrm{z})\end{array}$} \\
\hline & $m / z$ & $\begin{array}{l}\text { Tentative } \\
\text { assignation }\end{array}$ & \\
\hline \multirow{4}{*}{$\begin{array}{l}\text { m3 } \\
\text { (LAS34850) }\end{array}$} & $285(15)$ & {$\left[\mathrm{M}+\mathrm{HCOO}^{-}\right.$} & $239(100) ; 195(35)$ \\
\hline & $239(91)$ & {$[\mathrm{M}-\mathrm{H}]^{-}$} & $239(20) ; 195(100)$ \\
\hline & $195(100)$ & {$\left[\mathrm{M}-\mathrm{H}-\mathrm{CO}_{2}\right]^{-}$} & 195 (100); $83(10)$ \\
\hline & $137(5)$ & na & -- \\
\hline \multirow{3}{*}{$\begin{array}{l}\mathrm{m} 1 \\
(\mathrm{LAS} 101563)\end{array}$} & $203(20)$ & {$\left[\mathrm{M}+\mathrm{HCOO}^{-}\right.$} & -- \\
\hline & $157(100)$ & {$[\mathrm{M}-\mathrm{H}]^{-}$} & $157(15) ; 113(100)$ \\
\hline & $113(20)$ & {$\left[\mathrm{M}-\mathrm{H}-\mathrm{CO}_{2}\right]^{-}$} & -- \\
\hline $\mathrm{m} 2$ & $201(5)$ & {$\left[\mathrm{M}+\mathrm{HCOO}^{-}\right.$} & $201(50) ; 155(100)$ \\
\hline (2- & $155(100)$ & {$[\mathrm{M}-\mathrm{H}]^{-}$} & 155 (15); 83 (100) \\
\hline thiopheneglyoxylic & $89(7)$ & na & -- \\
\hline \multirow[t]{2}{*}{ acid) } & $83(55)$ & {$\left[\mathrm{C}_{4} \mathrm{H}_{3} \mathrm{~S}\right]^{-}$} & -- \\
\hline & $269(77)$ & {$\left[\mathrm{M}+\mathrm{HCOO}^{-}\right.$} & $269(75) ; 223(63) ; 179(100)$ \\
\hline $\mathrm{m}_{\mathrm{a}}$ & $223(61)$ & {$[\mathrm{M}-\mathrm{H}]^{-}$} & 223 (100); $179(100)$ \\
\hline (LAS101565) & $179(100)$ & {$\left[\mathrm{M}-\mathrm{H}-\mathrm{CO}_{2}\right]^{-}$} & $\begin{array}{l}\text { 178/179 (75/50); 146/147 (75/50); } 133(92) ; 107(80) ; 83 \\
(100)\end{array}$ \\
\hline
\end{tabular}

Data in parenthesis: relative abundance (\%) in the spectrum na: not assigned --: MS/MS spectrum not performed 
TABLE 4. Apparent kinetic parameters for the oxidative metabolism of ${ }^{14} \mathrm{C}$-LAS34823, ${ }^{14} \mathrm{C}$-phe-AB and ${ }^{14} \mathrm{C}$-glycAB. Test compounds $\left(0.5-100 \mu \mathrm{M}{ }^{14} \mathrm{C}-\right.$ phe- $\mathrm{AB}$ and 2-100 $\mu \mathrm{M}{ }^{14} \mathrm{C}$-LAS34823) were incubated in phosphate buffer ( $\mathrm{pH} 7.4)$ and with human liver microsomes in the presence and absence of NADPH.

\begin{tabular}{|c|c|c|c|c|c|c|}
\hline Metabolite & Test compound & System & $\begin{array}{l}\mathrm{K}_{\mathrm{m}} \\
(\mu \mathrm{M})\end{array}$ & $\begin{array}{l}V_{\max } \\
(\mathrm{pmol} / \mathrm{min} / \mathrm{mg} \\
\text { protein) }\end{array}$ & $\begin{array}{l}\mathrm{Cl}_{\mathrm{int}} \\
(\mu \mathrm{l} / \mathrm{min} / \mathrm{mg} \\
\text { protein) }\end{array}$ & $\begin{array}{l}\mathrm{K}_{\mathrm{h}} \\
\left(\mathrm{min}^{-1}\right)\end{array}$ \\
\hline M1 & ${ }^{14} \mathrm{C}$-LAS34823 & HLM+NADPH & $\begin{array}{l}\mathrm{K}_{\mathrm{m} 1} 2.1 \\
\mathrm{~K}_{\mathrm{m} 2} 65.5\end{array}$ & $\begin{array}{l}\mathrm{V}_{\max 1} 20.1 \\
\mathrm{~V}_{\max 2} 192.7\end{array}$ & $\begin{array}{l}9.6 \\
2.9\end{array}$ & $\begin{array}{l}\text { NA } \\
\text { NA }\end{array}$ \\
\hline & & Buffer & -- & -- & -- & 0.014 \\
\hline M2 & ${ }^{14} \mathrm{C}$-phe-AB & $\begin{array}{l}\text { HLM-NADPH } \\
+ \text { NADPH }\end{array}$ & $\begin{array}{l}0.43 \\
1.78\end{array}$ & $\begin{array}{l}37.7 \\
253.9\end{array}$ & $\begin{array}{l}87.7 \\
142.8\end{array}$ & $\begin{array}{l}0.012 \\
0.010\end{array}$ \\
\hline M3/m4 & $\begin{array}{l}{ }^{14} \mathrm{C} \text {-phe-AB } \\
{ }^{14} \mathrm{C} \text {-glyc-AB }\end{array}$ & $\begin{array}{l}\mathrm{HLM+NADPH} \\
\mathrm{HLM}+\mathrm{NADPH}\end{array}$ & $\begin{array}{l}22.6 \\
18.3\end{array}$ & $\begin{array}{l}283.4 \\
229.2\end{array}$ & $\begin{array}{l}12.5 \\
12.6\end{array}$ & $\begin{array}{l}\text { NA } \\
\text { NA }\end{array}$ \\
\hline M4/m5 & $\begin{array}{l}{ }^{14} \mathrm{C} \text {-phe-AB } \\
{ }^{14} \mathrm{C} \text {-glyc-AB }\end{array}$ & $\begin{array}{l}\mathrm{HLM+NADPH} \\
\mathrm{HLM+NADPH}\end{array}$ & $\begin{array}{l}4.6 \\
5.8\end{array}$ & $\begin{array}{l}106.0 \\
100.4\end{array}$ & $\begin{array}{l}23.0 \\
17.4\end{array}$ & $\begin{array}{l}\text { NA } \\
\text { NA }\end{array}$ \\
\hline $\mathrm{m} 2$ & ${ }^{14} \mathrm{C}$-glyc-AB & HLM+NADPH & 0.4 & 328.3 & 812.5 & 0.022 \\
\hline
\end{tabular}


TABLE 5. Summary of in vitro human P450 reaction phenotyping of aclidinium bromide metabolism obtained in recombinant human P450 isoforms and human liver microsomes.

\begin{tabular}{|c|c|c|c|c|}
\hline \multirow[b]{2}{*}{ Metabolite } & \multirow[b]{2}{*}{ Substrate } & \multirow{2}{*}{$\begin{array}{l}\text { Recombinant human P450 } \\
\text { isoforms } \\
\text { (n-fold basal activity) }\end{array}$} & \multicolumn{2}{|l|}{ Inhibition (\%) } \\
\hline & & & Chemical & Antibody \\
\hline m1 & ${ }^{14} \mathrm{C}$-glyc-AB & -- & no effect & no effect \\
\hline m2 & ${ }^{14} \mathrm{C}$-glyc-AB & $\begin{array}{l}\uparrow 2 \mathrm{D} 6(\approx 2.6 \text {-fold at } 5 \mu \mathrm{M} \text { and } 25 \mu \mathrm{M}) \\
\uparrow 3 \mathrm{~A} 4(\approx 1.4 \text {-fold at } 5 \mu \mathrm{M} \text { and } 25 \mu \mathrm{M})\end{array}$ & $\begin{array}{l}\text { ketoconazole: } 58 \% \\
\text { quercetin: } 25 \%\end{array}$ & CYP3A4: $52 \%$ \\
\hline \multirow{2}{*}{ M1 } & ${ }^{14}$ C-LAS34823 & $\uparrow 2 \mathrm{D} 6$ (> 40-fold) & quinidine: $>80 \%$ & CYP2D6: $>80 \%$ \\
\hline & ${ }^{14} \mathrm{C}$-phe-AB & 个2D6 (4.3-fold) & 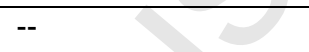 & -- \\
\hline M2 & ${ }^{14} \mathrm{C}$-phe-AB & $\uparrow 2 \mathrm{D} 6(2.2$-fold at $5 \mu \mathrm{M})$ & ketoconazole: $28 \%$ & CYP3A4: 23\% \\
\hline m3 & ${ }^{14} \mathrm{C}$-glyc-AB & $\downarrow 2 \mathrm{D} 6$ (0.7-fold at $5 \mu \mathrm{M})$ & no effect & no effect \\
\hline$m_{a}$ & ${ }^{14} \mathrm{C}-$ glyc-AB & no effect & -- & -- \\
\hline \multirow[t]{2}{*}{ M3/m4 } & ${ }^{14} \mathrm{C}$-phe-AB & -- & $\begin{array}{l}\text { ketoconazole: }>77 \% \\
\text { quercetin: } 44 \% \\
\text { quinidine: } 20 \%\end{array}$ & $\begin{array}{l}\text { CYP3A4:>70\% } \\
\text { CYP2D6: } 31 \%\end{array}$ \\
\hline & ${ }^{14} \mathrm{C}$-glyc-AB & -- & ketoconazole: $>35 \%$ & $\begin{array}{l}\text { CYP2D6: 34\% } \\
\text { CYP3A4: 32\% }\end{array}$ \\
\hline \multirow[b]{2}{*}{ M4/m5 } & ${ }^{14} \mathrm{C}-$ phe-AB & $\uparrow 2 \mathrm{D} 6$ (>6.5-fold) & quinidine: $>77 \%$ & CYP2D6: 62\% \\
\hline & ${ }^{14} \mathrm{C}$-glyc-AB & $\begin{array}{l}\uparrow 2 \mathrm{D} 6 \text { (>1.6-fold at } 5 \mu \mathrm{M},>3.2 \text {-fold at } \\
25 \mu \mathrm{M}) \\
\uparrow 1 \mathrm{~A} 1(>1.8 \text {-fold at } 25 \mu \mathrm{M})\end{array}$ & quinidine: $>48 \%$ & CYP2D6: 40\% \\
\hline
\end{tabular}

See Sections 2.5 and 2.6 for incubation details

--: metabolite not detected at any of the concentrations assayed.

$\mathrm{M} 5 / \mathrm{m} 6$ and $\mathrm{M} 6 / \mathrm{m} 7$ were not detected in the experiments.

$\uparrow / \downarrow$ : increased/decreased activity with human recombinant CYP compared to control incubation (insect control). The remaining human rCYPs did not have any influence on metabolite formation.

No effect: enzyme activity was not significantly inhibited (<20\% inhibition) against control incubations. 
Figure 1

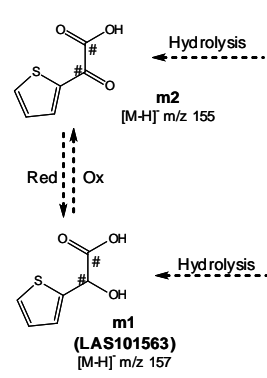

(LAS101563)
$[\mathrm{M}-\mathrm{H}] \mathrm{m} / \mathrm{z} 157$
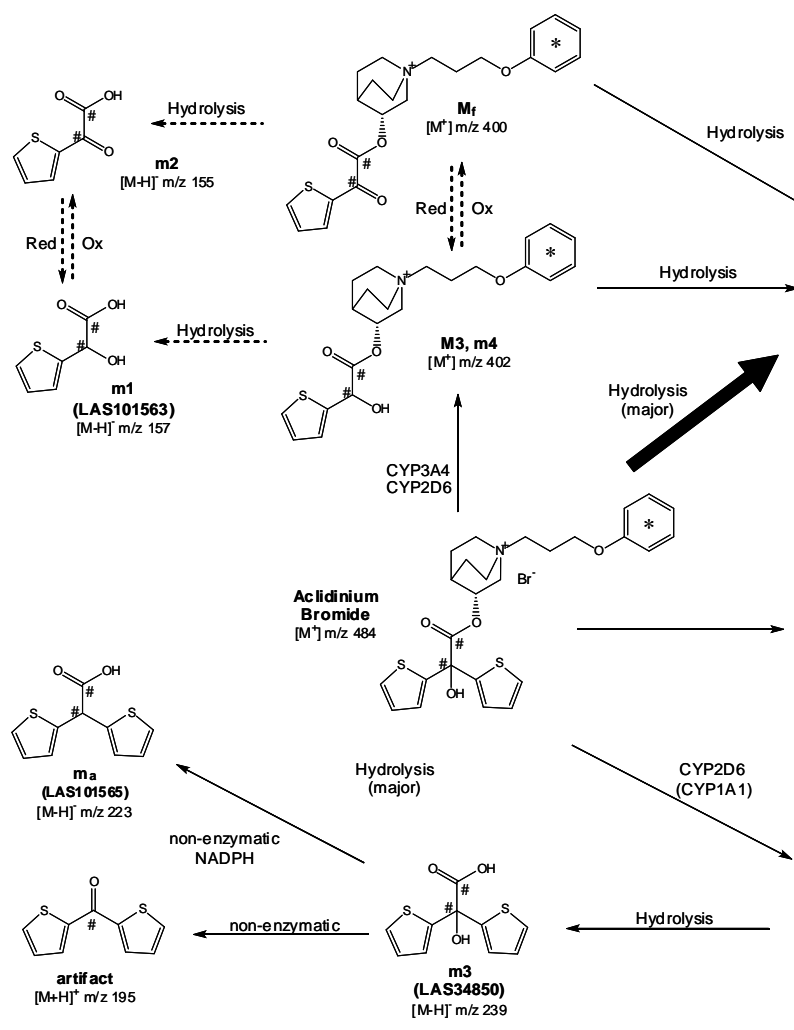

*
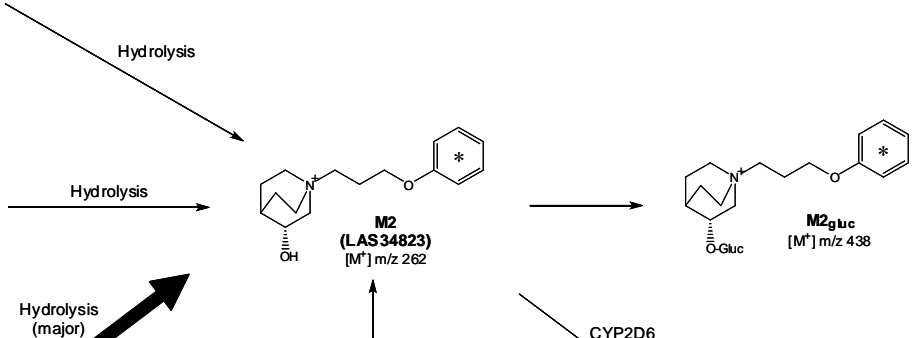

(major)

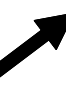

$\begin{array}{ll}\text { Oे } & \text { (LAS34823) } \\ {\left[\mathrm{M}^{+}\right] \mathrm{m} / \mathrm{z} 262}\end{array}$

$M 2_{\text {gluc }}$
$\left[M^{+}\right] \mathrm{m} / \mathrm{z} 438$
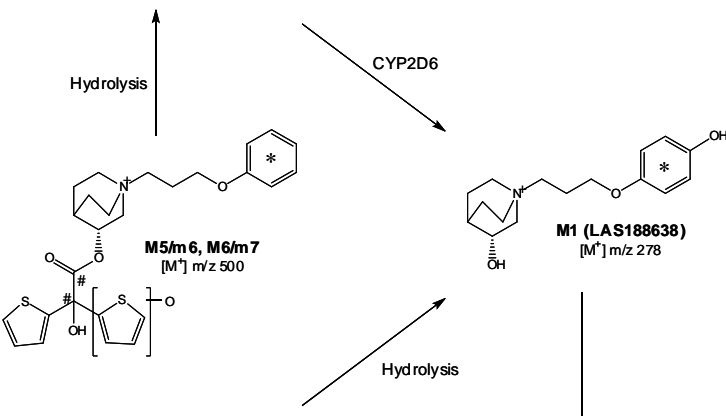

$\left[\mathrm{M}^{+}\right] \mathrm{m} / \mathrm{z} 278$
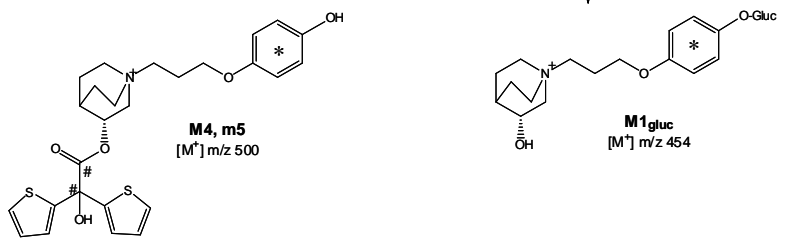
Figure 2

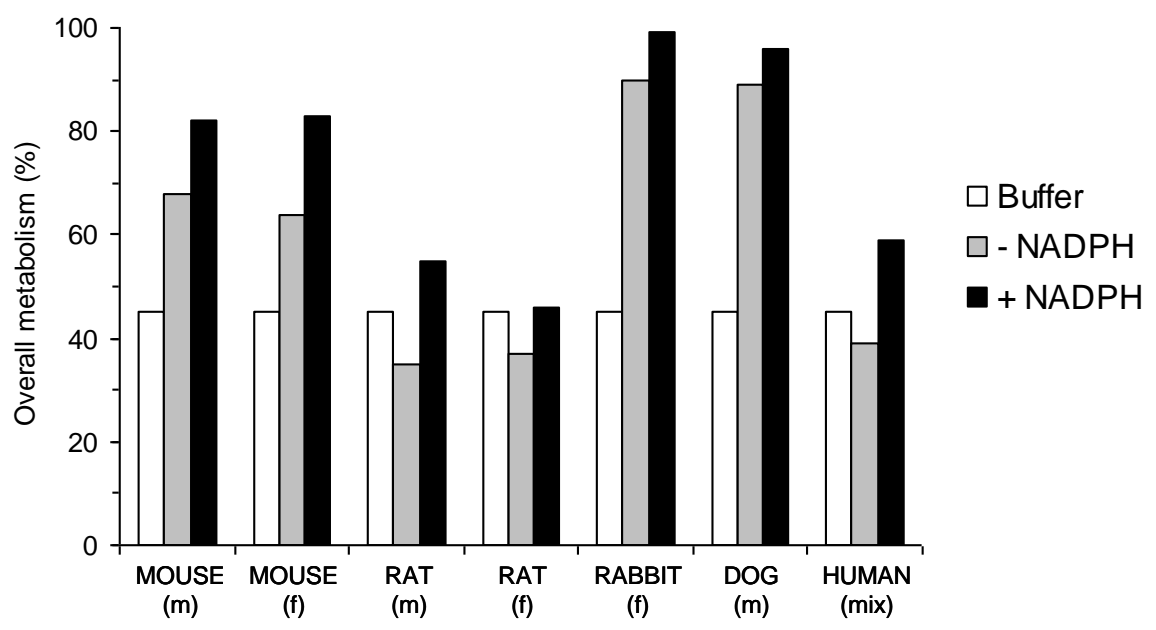


Figure 3
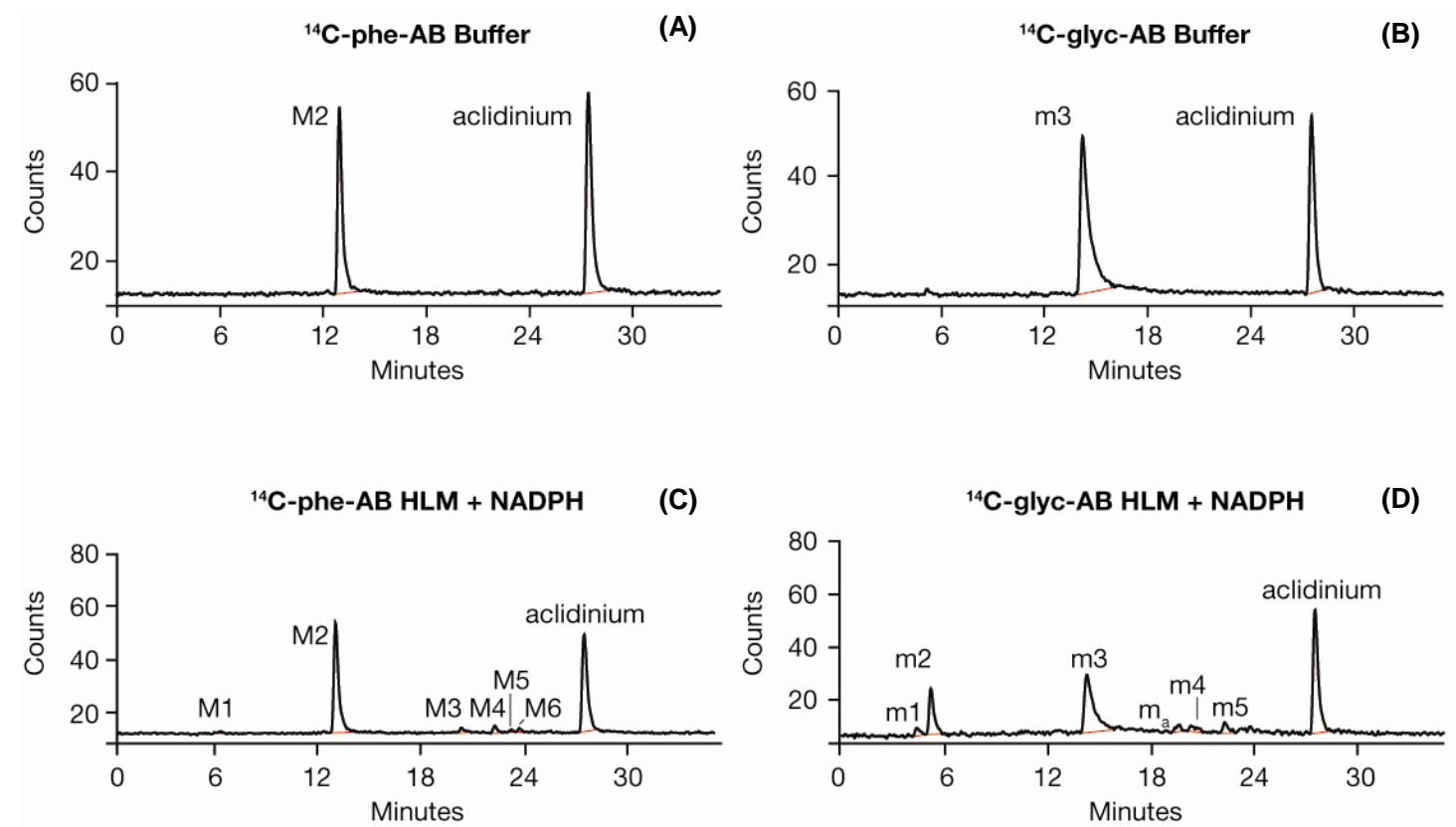

${ }^{14}$ C-LAS34823 HLM + NADPH

(E)

${ }^{14}$ C-LAS34850

(F)
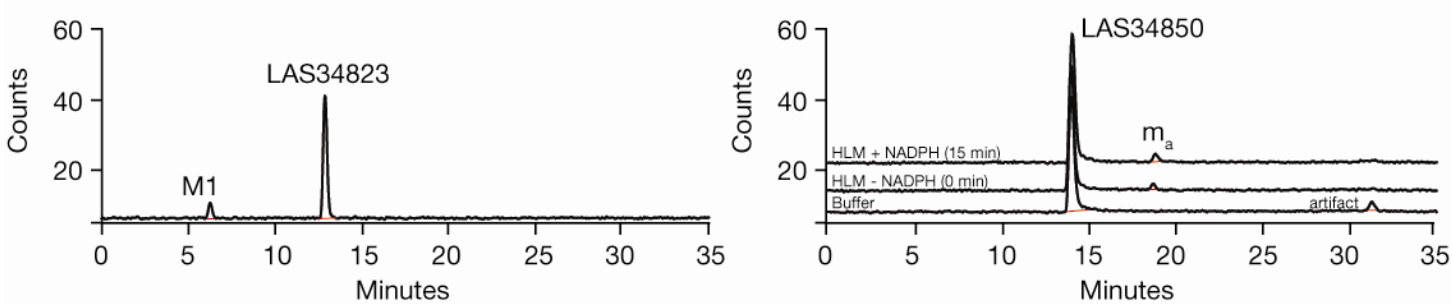


\section{Figure 4}
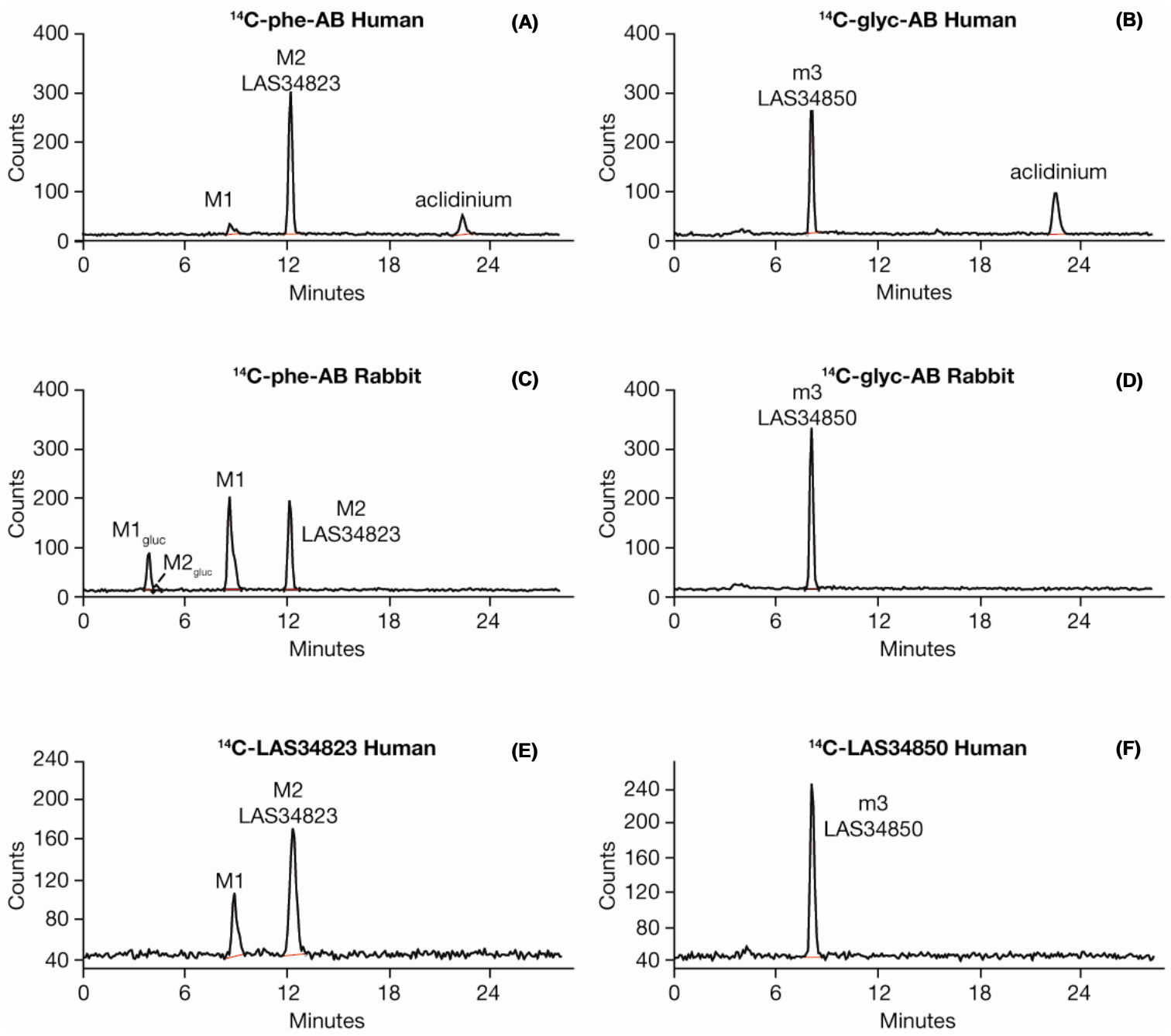
Figure 5
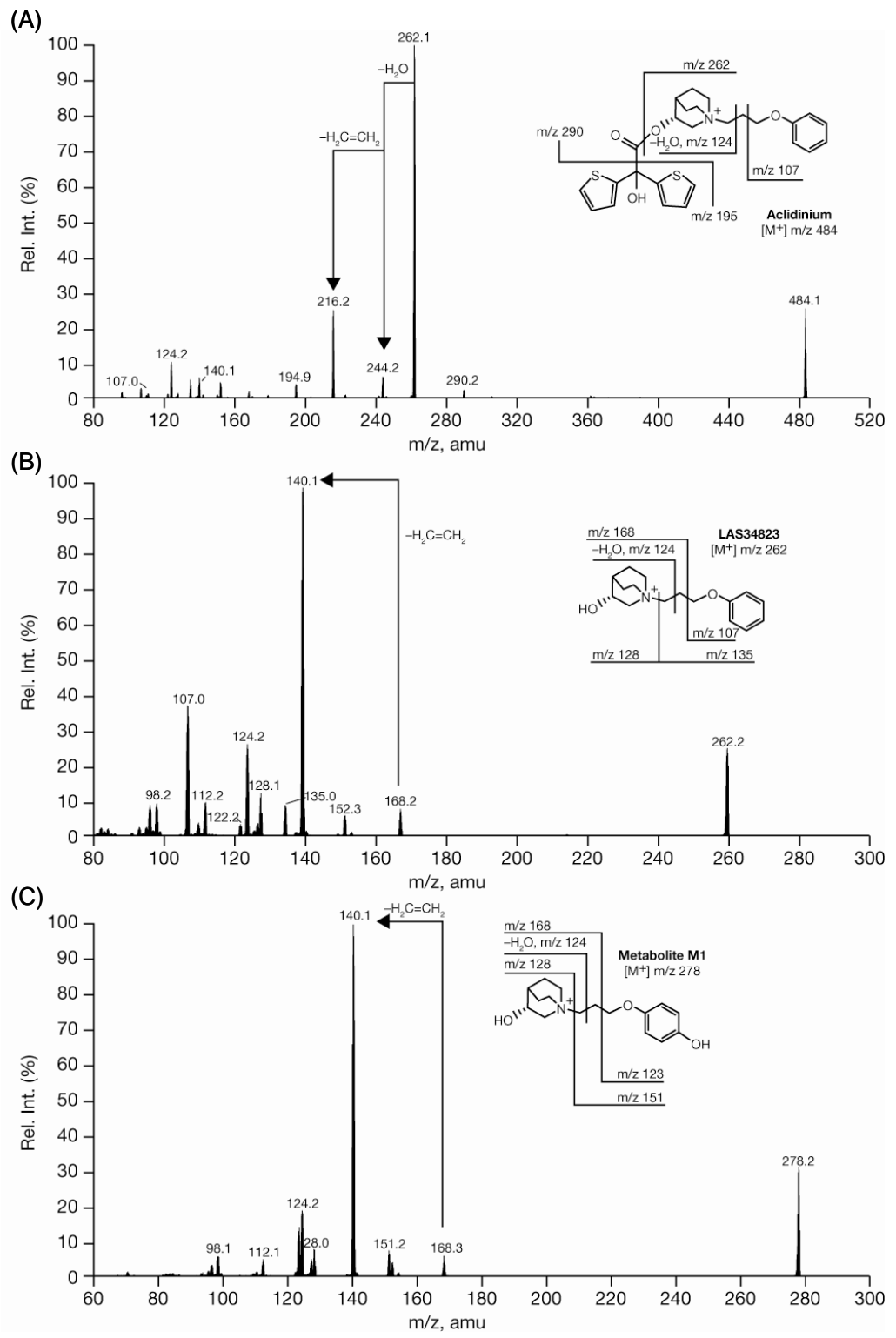
Figure 6
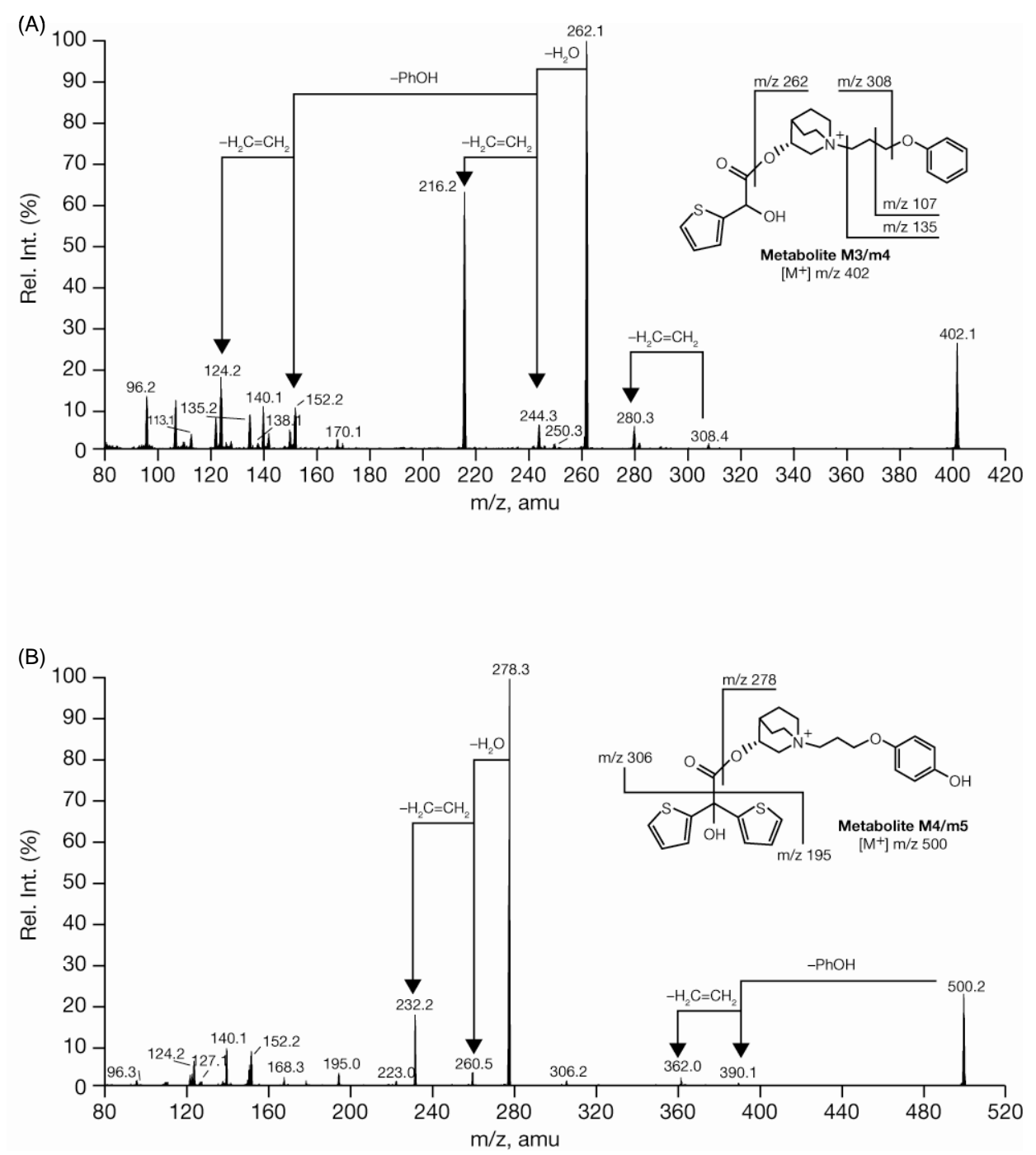
Figure 7
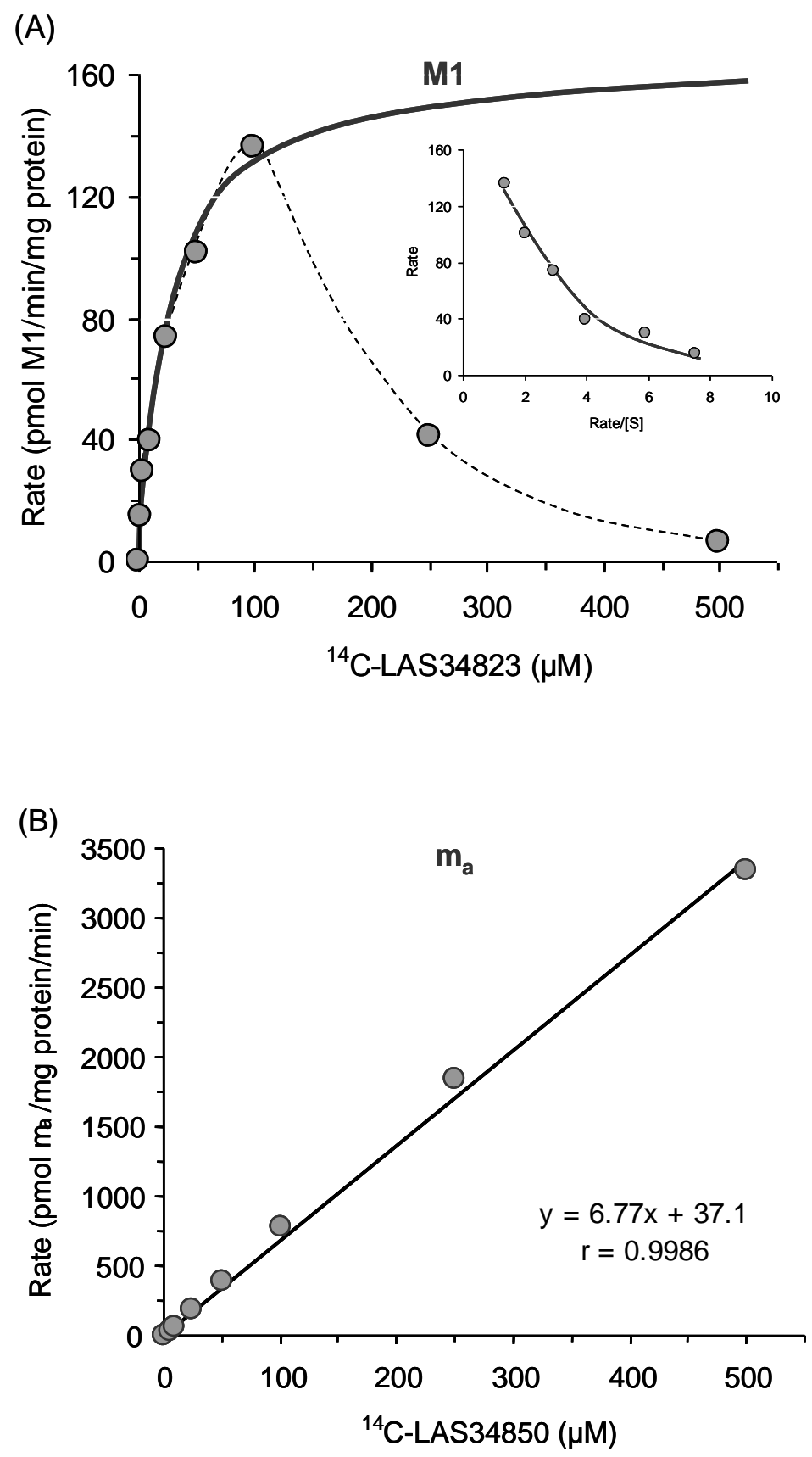
Figure 8
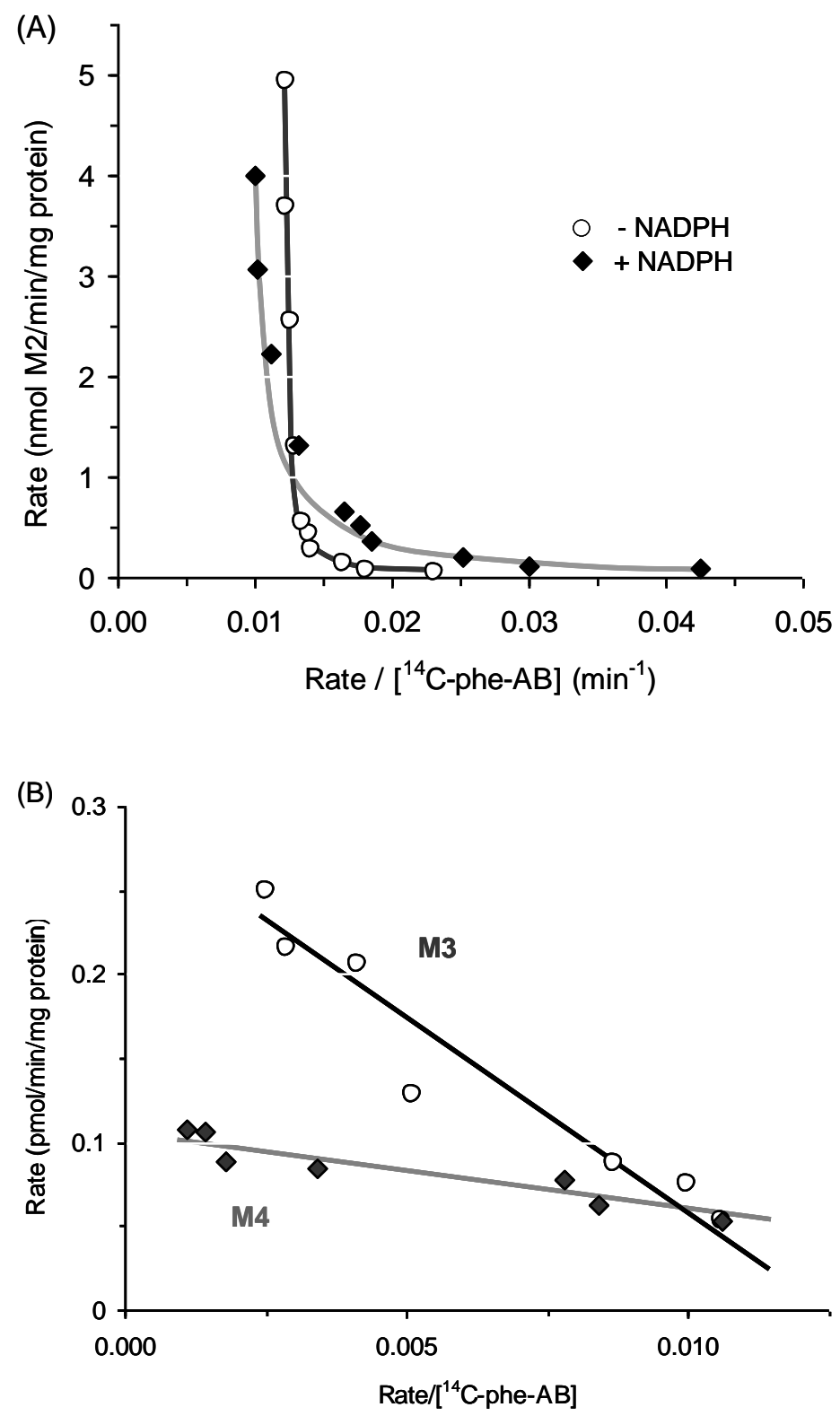
Figure 9
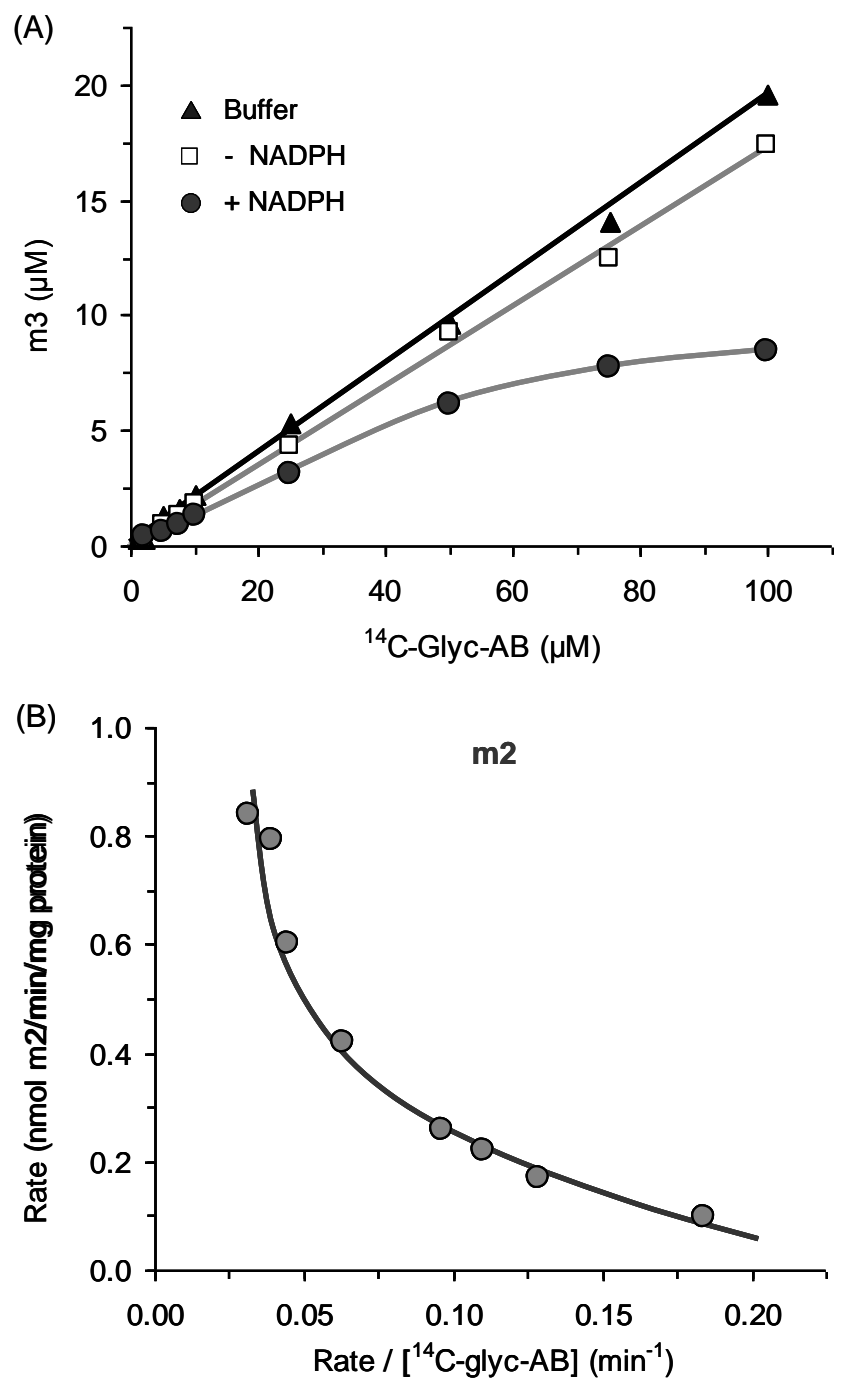


\section{Graphical abstract}

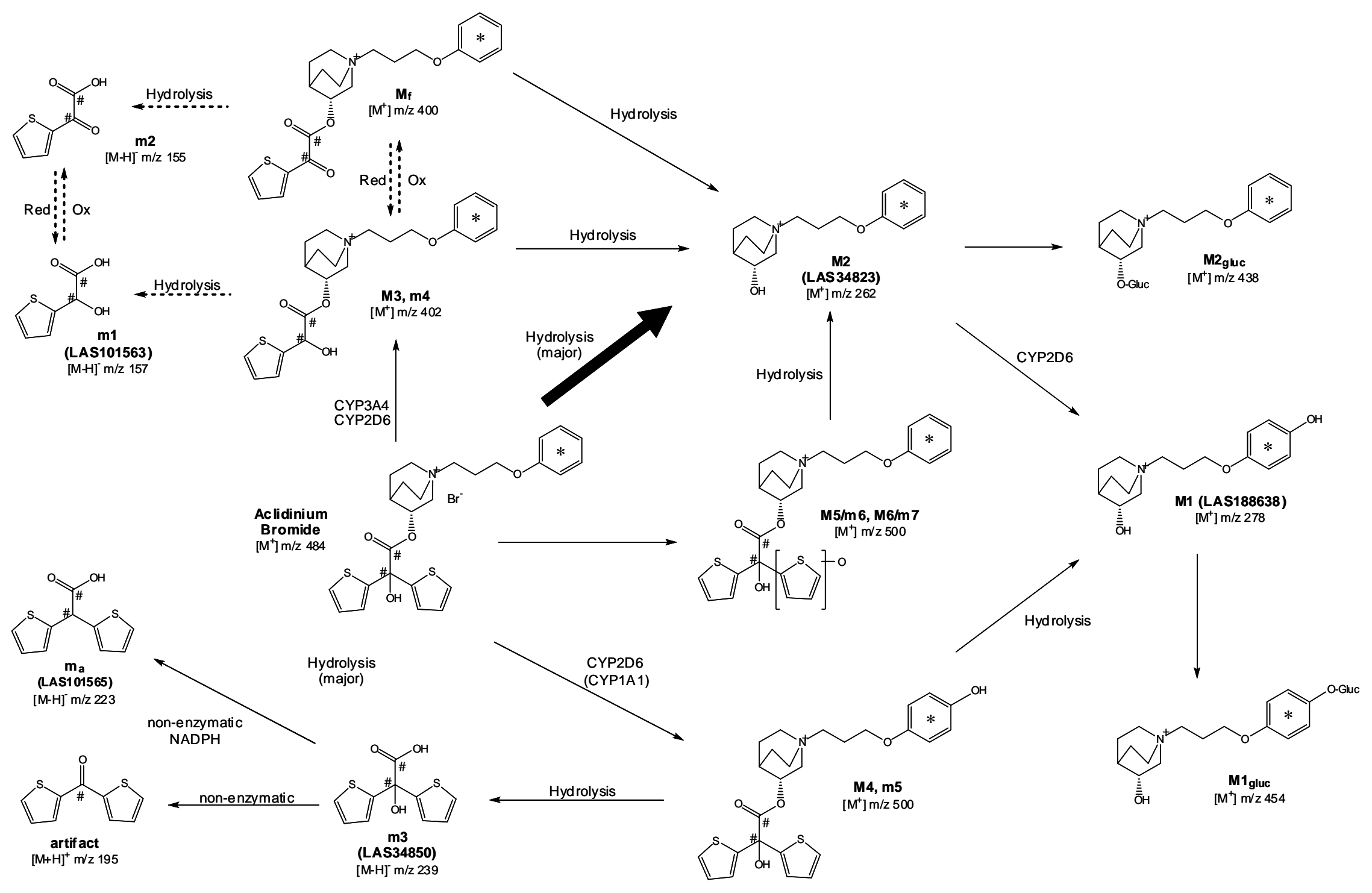

